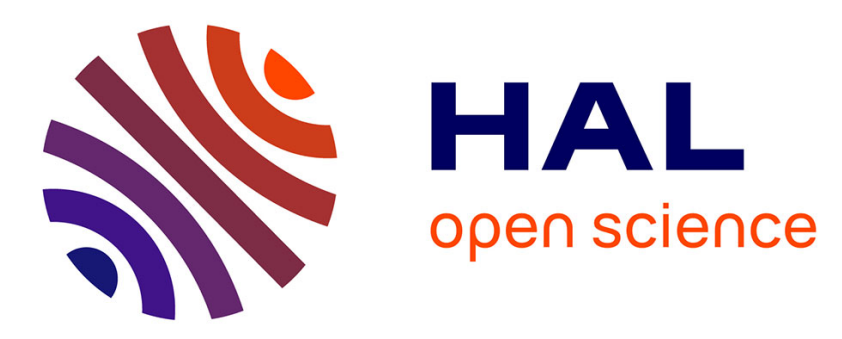

\title{
Experimental Investigation of Pilot-Fuel Combustion in Dual-Fuel Engines, Part 1: Thermodynamic Analysis of Combustion Phenomena Highlights
}

Aleš Srna, Beat von Rotz, Kai Herrmann, Konstantinos Boulouchos, Gilles Bruneaux

\section{To cite this version:}

Aleš Srna, Beat von Rotz, Kai Herrmann, Konstantinos Boulouchos, Gilles Bruneaux. Experimental Investigation of Pilot-Fuel Combustion in Dual-Fuel Engines, Part 1: Thermodynamic Analysis of Combustion Phenomena Highlights. Fuel, 2019, 255, pp.115642. 10.1016/j.fuel.2019.115642 . hal02296925

\section{HAL Id: hal-02296925 \\ https://hal-ifp.archives-ouvertes.fr/hal-02296925}

Submitted on 25 Sep 2019

HAL is a multi-disciplinary open access archive for the deposit and dissemination of scientific research documents, whether they are published or not. The documents may come from teaching and research institutions in France or abroad, or from public or private research centers.
L'archive ouverte pluridisciplinaire HAL, est destinée au dépôt et à la diffusion de documents scientifiques de niveau recherche, publiés ou non, émanant des établissements d'enseignement et de recherche français ou étrangers, des laboratoires publics ou privés. 


\title{
1 Title:
}

2 Experimental Investigation of Pilot-Fuel Combustion in Dual-Fuel Engines, Part 1: Thermodynamic

3 Analysis of Combustion Phenomena

\section{Authors:}

\author{
Aleš Srna**1, Beat von Rotz ${ }^{1}$, Kai Herrmann ${ }^{2}$, Konstantinos Boulouchos ${ }^{3}$, Gilles Bruneaux ${ }^{4}$ \\ 1. Paul Scherrer Institute, Energy and Environment Division, Forschungstrasse 111, CH-5232 Villigen PSI, \\ Switzerland \\ 2. University of Applied Sciences Northwestern Switzerland, Institute of Thermal and Fluid Engineering, \\ School of Engineering, Klosterzelgstrasse 2, CH-5210 Windisch, Switzerland \\ 3. ETH Zürich, Institute for Energy Technology, Laboratory for Aerothermochemistry and Combustion \\ Systems, Sonneggstrasse 3, CH-8092 Zürich, Switzerland \\ 4. IFP Energies nouvelles, 1 et 4 avenue de Bois Préau, 92852 Rueil-Malmaison, France; Institut Carnot \\ IFPEN Transports Energie
}

*Corresponding author (A. Srna): ales.srna@psi.ch

\begin{abstract}
The pilot-fuel auto-ignition and combustion in compressed methane/air mixtures have been investigated. Experiments were performed in an optically accessible Rapid Compression-Expansion Machine featuring quiescent charge conditions and a single-hole coaxial diesel injector mounted on the cylinder periphery. It enabled thermodynamic analysis of the pilot-fuel combustion without these phenomena being masked by the rapid premixedflame propagation like in the engine test rigs with turbulent charge. The aim of this study was to elucidate the firstorder influences of charge and pilot-fuel parameters on the ignition delay and transition into the premixed flame propagation. For this purpose, a comprehensive measurement matrix including variations of the premixed fuel equivalence ratio, charge temperature, and oxygen content as well as the variation of pilot injection duration has been considered. The heat release rate (HRR) metrics describing the pilot-fuel combustion duration, peak HRR, and cumulative HRR during the pilot-fuel combustion have been derived. Correlations of the HRR metrics to the ignition delay, pilot-fuel mixing state at ignition and the volume of the pilot-fuel jet were investigated. Methane was found to increase the ignition delay and prolong the pilot-fuel combustion duration. This effect is amplified for pilot-injection strategies with leaner pilot-fuel mixtures at ignition, or in case of reduced charge oxygen content. Despite the reduced pilot-fuel reactivity the co-combustion of entrained methane leads to higher peak-HRR, except in the reduced charge oxygen cases, where the excessively reduced mixture reactivity with the introduction of methane leads even to a reduced peak-HRR.
\end{abstract}

The phenomenology of the dual-fuel combustion process is described in Part 1, whereas Part 2 of this work aims at improving the understanding of the underlying processes by application of advanced optical diagnostic methods.

\section{Keywords:}

Dual-fuel engines; natural-gas engines; combustion mode transition; autoignition; tracer-PLIF; combustion phenomenology 


\section{Highlights:}

- Pilot-fuel ignition delay prolonged with higher methane concentrations

- Transition from auto-ignition to premixed flame characterized by combustion metrics

- Prolonged pilot-fuel combustion duration in the presence of methane

- Higher peak-HRR due to the simultaneous pilot-fuel and entrained methane combustion

- Prolonged pilot-fuel burning and lower peak-HRR in dual-fuel cases with EGR

\section{Introduction}

In recent years, many gas-fueled engine concepts are emerging, for transportation as well as stationary applications. They are seen to be an attractive solution to meet current and upcoming emission legislation. Application of natural gas is advantageous regarding the associated $\mathrm{CO}_{2}$ reduction, high resistance to auto-ignition (knock) and low sooting propensity. Especially in large engine applications ranging from heavy-duty to marine and stationary, lean burn combustion systems with potential for lower pollutant emission at diesel-engine comparable efficiencies are employed. Advanced ignition systems like pilot-injection or pre-chamber spark-ignition are utilized to ensure stable and fast combustion. In combination with further measures such as exhaust gas recirculation and variable valve timing to additionally increase the cycle efficiency, this technology is promising as a solution in short to midterm perspective to fulfill the stricter emission legislation.

Studies in full engines [1-4], single cylinder engines [5-11], optical engines [12-16] and more generic devices such as rapid compression machines [17-21] are documented. Most of the engine related studies were focusing on the analysis of the heat release rate stability and characteristics as well as exhaust gas emissions. A common approach is substituting part of the diesel fuel (reduction of injection duration) with premixed methane showing a potential for significant $\mathrm{NO}_{\mathrm{x}}$ and soot reduction. Nevertheless, especially under low loads, the combustion duration is considerably prolonged resulting in worse thermal efficiency [1-3, 5-8]. The adverse effect seen in dual-fuel engines (gas mode operation) is obviously the increase in UHC emission which shows up to two orders of magnitude higher emission levels compared to diesel-only operation. These products of the incomplete combustion consist up to $90 \%$ of methane [2], being a major greenhouse gas pollutant. Several studies have shown the potential of increasing the injection duration to mitigate UHC emissions as well as to improve the thermal efficiency $[2,3,9,22]$. However, such an approach leads to substantially increased soot and $\mathrm{NO}_{\mathrm{x}}$ emissions $[2,5,7,8]$. This tradeoff clearly motivates further studies of improved engine geometries and advanced engine control systems and elucidates the need for improved fundamental and phenomenological understanding of the combustion as well as emissions formation processes in dual-fuel engines.

Dual-fuel combustion of the pilot-fuel in a lean natural gas mixture is a highly complex process involving short transient pilot fuel injection into the premixed gaseous fuel charge, pilot-fuel autoignition and burning, combustion mode transition, and premixed flame propagation. A conceptual description of the dual-fuel combustion by three overlapping heat release sources was proposed by Karim et al. [23]. First, the rapid combustion of the premixed pilot-fuel occurs. During the second and third stage, the gaseous fuel in the immediate vicinity of the ignition locations within the pilot fuel spray is burnt, followed by the combustion of premixed fuel by turbulent flame propagation. Several optical, numerical and engine studies have addressed the influence of methane on the ignition delay and reported the strong inhibiting effect on ignition through chemical interaction [16, 20, 21, 24-27]. More specifically, the low-temperature reactivity in pilot-fuel lean regions is considerably retarded leading to an overall increased ignition delay and lower pilot-fuel mixture reactivity. Nevertheless, little is known about the influence of methane on the processes after ignition. While the premixed flame is well understood from the spark ignited engines research and studied even in the context of dual-fuel engines [14, 28], the transition behavior of the pilot-fuel autoignition before established flame propagation has been rarely described in the literature. Only the recent work by Rochussen et al. [28] investigated the rate of burnt zone growth in an optically accessible dual-fuel engine. Recent work by Soriano et al. [29, 30] investigated dual-fuel combustion transition numerically 
It is understood from the optical studies that the transition-phase strongly influences the shape of the premixed combustion flame front (toroidal, radial) as well as the time instant and flame surface area when the premixed flame onsets [31]. Some engine studies studied the transition phase phenomenology by the HRR analysis [32]. Nevertheless, in engines, the HRR from the transition phase is masked by the rapid premixed flame propagation, thus making it challenging to extract information of the pilot-fuel combustion phase without application of advanced optical diagnostics. Therefore, to correctly reproduce the experimental observations the present phenomenological models of dual-fuel combustion strongly rely on several assumptions and parameter tuning.

Understanding the transition phase in the context of reactivity controlled compression ignition (RCCI) combustion concept has been further progressed [33-37]. This combustion concept utilizes two liquid fuels with different reactivity which are blended in the combustion chamber to generate a non-uniformity regarding the mixture autoignition characteristics. By quantifying the stratification of high-reactivity fuel, it was shown that the combustion proceeds via an auto-igniting flame front following the reactivity gradients. Auto-ignition of least reactive mixtures is accelerated through compression heating by the burnt gases. Therefore, the combustion duration and peak pressure rise rates are directly governed by the stratification of ignition time [33].

The scope of this study is to investigate the dual-fuel combustion transition phase from the pilot-fuel ignition until established premixed flame propagation. Hereby, two distinct characteristics are particularly different from the RCCI combustion using liquid fuels: first, the chemical interaction of the premixed methane considerably changes the reactivity of the pilot-fuel, and second, the existence of the premixed flame. The transition phase, coupling ignition to premixed flame propagation, strongly influences the shape of the established premixed flame and therefore strongly influences the combustion duration.

This publication (Part 1) investigates the phenomenology of the heat-release rate characteristics and its relation to the fuel-stratification prior to ignition. The heat-release rate (HRR), in the time interval between ignition and established premixed flame, has been analyzed by defining combustion metrics (duration, peak, total energy) in order to characterize the combustion transition process. The HRR analysis has been supplemented by quantitative tracer-PLIF measurements to assess the pilot-fuel mixing distribution prior to ignition. A comprehensive matrix of measurements including variations of charge temperature at injection, charge oxygen content, premixed methane equivalence ratio, pilot injection duration and pressure, including several cross-variations, was acquired.

This publication is structured as follows: First, the experimental test rig and the HRR analysis procedure with the definition of HRR metrics are presented. The results section emphasizes the influence of charge and combustion parameters on the HRR metrics like ignition delay, pilot-fuel combustion duration, and peak-HRR. Finally, correlations of different combustion parameters are discussed while experimental results corroborate conclusions in regard to parameter influence on the combustion during the pilot-fuel burning.

Part 2 of this work will focus on improving the understanding of the underlying processes governing the transition. For this purpose, the combustion process was investigated using high-fidelity optical diagnostics $\left(\mathrm{CH}_{2} \mathrm{O}-\mathrm{PLIF}\right.$, Schlieren, $\mathrm{OH}^{*}$ ), supported with homogeneous-reactor and laminar flame speed simulations.

\section{Experimental setup}

\subsection{Rapid Compression Expansion machine}

A Rapid Compression Expansion Machine (RCEM) has been utilized to compress the homogeneous methane/air charge in order to achieve engine relevant conditions at the time of pilot-fuel injection. This RCEM is a generic freefloating piston test rig (bore: $84 \mathrm{~mm}$, variable stroke: $120-249 \mathrm{~mm}$ ) with optical accessibility through piston and cylinder head windows. A brief description of the machine and its operation principle is provided here, while further descriptions are available in $[18,20,38]$. 
The machine operates in a single cycle mode (compression and partial expansion). The drive energy for the piston motion is provided through the compressed air charge acting on a system of hydraulically coupled working piston and mass-balance piston, which move in the opposite directions to enable vibration-free operation. Due to the absence of mechanical piston coupling to a flywheel, the piston acceleration is governed by the pressure difference between the driving volume and combustion chamber. The subsequent piston motion resembles a pendulum-like swing with a fast ejection of the piston towards the top dead center (TDC). The piston decelerates as the pressure in the combustion chamber builds up and swings back towards the equilibrium position.

The RCEM combustion chamber has a cylindrical geometry with a flat cylinder head and virtually flat piston (2.2 mm piston bowl, Figure 1). A standard common-rail diesel injector body (Bosch CRI2-16) equipped with a custom $100 \mu \mathrm{m}$ diameter single-hole conical coaxial nozzle tip (KS 1.5, discharge coefficient $\mathrm{C}_{\mathrm{d}}=0.80$ ) has been used to admit the pilot fuel. The injector was mounted on the cylinder periphery at $5^{\circ}$ axis inclination towards the piston. The nozzle orifice position was located at a distance of $5 \mathrm{~mm}$ from the cylinder head and $42.5 \mathrm{~mm}$ from the cylinder axis.

Boundary conditions in this RCEM are precisely controlled and were investigated in previous studies. PIV investigation of the flow field during the compression reported quiescent conditions throughout the cycle [38]. The charge temperature in the BDC is controlled with a multi-zone electric heating system of the cylinder walls and cylinder head. BDCemperature homogeneity better than $\sigma=3 \mathrm{~K}$ can be achieved [18]. Methane is admitted directly into the combustion chamber using a hollow-core injector (Continental) and the injected quantity controlled by adjusting the injector opening time $(22-45 \mathrm{~ms})$. Sufficient time for mixing with air is allowed before compression is initiated. Methane mixture homogeneity in the present configuration has been tested in [20], with the volumeaverage standard deviation $\sigma=0.067$ of methane concentration from homogeneous mixture reported.

The RCEM instrumentation enables a precise recording of the piston position (resolution $0.02 \mathrm{~mm}$ ) and cylinder pressure (flush-mounted piezoelectric transducer, Kistler $7061 \mathrm{~B}, 0-250 \mathrm{bar}$ ) at a rate of $100 \mathrm{kHz}$. The piezoelectric sensor is pegged using a precise absolute pressure transducer (Kistler 4075A10, 0-10 bar) in a fast-switching adapter (Kistler 741A). General RCEM specifications are given in Table 1.

Table 1: General specifications of the RCEM.

\begin{tabular}{|c|c|}
\hline Cylinder bore & $84 \mathrm{~mm}$ \\
\hline Stroke & Adjustable, $120-249 \mathrm{~mm}$ \\
\hline Displaced volume & $0.67-1.38 \mathrm{dm}^{3}$ \\
\hline Realizable compression ratio & $5-25$ \\
\hline Charge intake pressure & $1.1-2 \mathrm{bar}$ \\
\hline Cylinder head geometry & flat \\
\hline Piston bowl geometry & Top hat, Ø52 mm x $2.2 \mathrm{~mm}$ \\
\hline $\begin{array}{l}\text { Cylinder liner and head } \\
\text { heating }\end{array}$ & $\begin{array}{l}\text { Multi-zone electric, up to } \\
450 \mathrm{~K}\end{array}$ \\
\hline Optical access & $\begin{array}{l}\text { Piston window, Ø52 } \mathrm{mm} \\
\text { Cylinder head window } \\
\varnothing 52 \mathrm{~mm} \\
\text { Lateral window } \varnothing 36 \mathrm{~mm}\end{array}$ \\
\hline Pilot fuel injection & 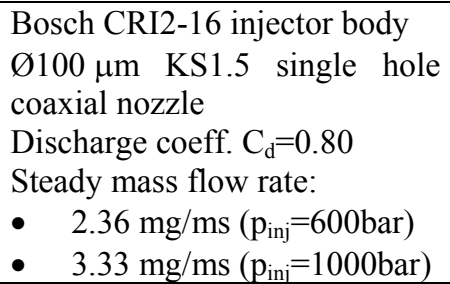 \\
\hline Methane injector & $\begin{array}{l}\text { Continental outwards opening } \\
\text { hollow-cone nozzle }\end{array}$ \\
\hline
\end{tabular}




\subsection{Experimental conditions}

3 In this study, the RCEM has been operated at maximal BDC displacement setting $\left(1.38 \mathrm{dm}^{3}\right.$ displacement, $249 \mathrm{~mm}$ 4 BDC clearance to the cylinder head) to have a sufficient TDC clearance for minimizing the pilot spray interaction 5 with walls.

6 The free-floating piston design of the machine results in an inherently uncertain piston motion which will be influenced by the combustion pressure rise, variation in the driving gas pressure, and friction of the piston motion. The operation strategy has been selected based on preparatory studies. High compression ratio and pilot injection early before TDC have been selected to ensure high repeatability of the conditions at the SOI and to extend the operational range of the machine w.r.t. maximal charge equivalence ratio. Figure 4 shows the piston position, cylinder pressure trace, and estimated bulk temperature, along with an indication of SOI to demonstrate the RCEM operation strategy. The cylinder charge bulk temperature evolution has been estimated using a thermodynamic model accounting for compression, wall heat losses, crevice volumes, and piston rings blow-by, as explained in more detail in section 2.3 "Heat Release Rate analysis".

15 The pilot fuel injection has been triggered based on the pressure signal. A threshold of 25 bar has been selected leading to SOI approximately $3.5 \mathrm{~ms}$ before TDC. The experimental matrix consists of three variations of experimental parameters as summarized in Table 2. First, a variation of the injection duration (ET variation) at 600 bar injection pressure has been acquired at three different temperatures at the start of injection $\left(T_{\text {SoI }}\right): 775 \mathrm{~K}$, $810 \mathrm{~K}$, and $850 \mathrm{~K}$, at the cylinder wall temperatures of $343 \mathrm{~K}, 363 \mathrm{~K}$, and $383 \mathrm{~K}$, respectively. The charge temperature in the $\mathrm{BDC}$ corresponds to the cylinder wall temperature. Hydraulic injection duration between $0.4-$ $0.77 \mathrm{~ms}$ has been considered. Second, a set of short $(\mathrm{ET}=300 \mu \mathrm{s}$, hydraulic duration $0.40 \mathrm{~ms})$ injections at higher injection pressure $\mathrm{p}_{\text {inj }}=1000 \mathrm{bar}$ have been performed at the same range of $\mathrm{T}_{\text {Sol }}$. The third variation investigated the influence of reduced oxygen content. Charge air has been diluted with nitrogen resulting in charge oxygen content of $18 \%$ or $15 \%$. Injection pressure and ET were kept constant at $\mathrm{p}_{\mathrm{inj}}=600 \mathrm{bar}$ and $\mathrm{ET}=400 \mu \mathrm{s}$, respectively, and $\mathrm{T}_{\mathrm{SOI}}$ of $810 \mathrm{~K}$ and $850 \mathrm{~K}$ were considered.

The injection rate profile of the pilot injector has been characterized for the selected rail pressures and energizing times using a "Bosch tube" type injection rate analyzer. The measured steady fuel injection rate at 30 bar tube pressure was $2.36 \mathrm{mg} / \mathrm{ms}$ and $3.33 \mathrm{mg} / \mathrm{ms}$ for 600 bar and 1000 bar rail pressure, respectively. The duration of the injector opening and closing transient was $140 \mu \mathrm{s}$ (600 bar) and $110 \mu \mathrm{s}$ (1000 bar), respectively. 
Table 2: Overview of the operating conditions. Values in the $2^{\text {nd }}$ row relate to the variation of $T_{\text {SOI }}$ and $E T$, values in the $3^{\text {rd }}$ row describe the variation of the $P_{\text {inj }}$, and values in the $4^{\text {th }}$ row show the EGR cases (reduced oxygen content). The parameters varied in each column are printed bold.

\begin{tabular}{|c|c|c|c|}
\hline & $\mathbf{T}_{\text {SOI }} / \mathbf{E T}$ variation & $\mathbf{P}_{\text {inj }}$ variation & $\begin{array}{c}\text { EGR variation } \\
{\left[\mathrm{O}_{2}\right]} \\
\end{array}$ \\
\hline BDC displacement & \multicolumn{3}{|c|}{$1.38 \mathrm{dm}^{3}$} \\
\hline Charge intake pressure & \multicolumn{3}{|c|}{$1.2 \mathrm{bar}$} \\
\hline Stroke & \multicolumn{3}{|c|}{$236.5 \mathrm{~mm} \pm 1 \mathrm{~mm}$} \\
\hline Compression ratio & \multicolumn{3}{|c|}{20} \\
\hline Pressure at SOI $\left(\mathrm{P}_{\mathrm{SOI}}\right)$ & \multicolumn{3}{|c|}{25 bar } \\
\hline BDC temperature & \multicolumn{2}{|c|}{$343,363,383 \mathrm{~K}$} & $363,383 \mathrm{~K}$ \\
\hline $\begin{array}{l}\text { Temperature at SOI } \\
\left(\mathrm{T}_{\mathrm{SOI}}\right)\end{array}$ & \multicolumn{2}{|c|}{$775,810,850 \mathrm{~K}$} & $810,850 \mathrm{~K}$ \\
\hline $\begin{array}{l}\text { Pilot injector } \\
\text { energizing time (ET) }\end{array}$ & $300,400,500 \mu s$ & $300 \mu \mathrm{s}$ & $400 \mu \mathrm{s}$ \\
\hline Pilot injection duration & $0.40,0.58,0.77 \mathrm{~ms}$ & $0.45 \mathrm{~ms}$ & $0.58 \mathrm{~ms}$ \\
\hline Pilot injection pressure & $600 \mathrm{bar}$ & 1000 bar & $600 \mathrm{bar}$ \\
\hline $\begin{array}{l}\text { Injected pilot-fuel } \\
\text { mass [mg] }\end{array}$ & $0.64,1.18,1.81 \mathrm{mg}$ & $1.21 \mathrm{mg}$ & $1.18 \mathrm{mg}$ \\
\hline $\begin{array}{l}\text { Charge oxygen content } \\
\%\left[\mathrm{O}_{2}\right]\end{array}$ & 21 & 21 & 18,15 \\
\hline $\begin{array}{l}\text { Methane/air mixture } \\
\text { equivalence ratio } \\
\left(\varphi_{\mathrm{CH} 4}\right)\end{array}$ & $\begin{array}{c}0,0.33,0.48,0.53 \\
0.58,0.66\end{array}$ & $0,0.48,0.53,0.58$ & $\begin{array}{l}18 \%\left[O_{2}\right]: 0,0.56,0.62,0.68 \\
15 \%\left[O_{2}\right]: 0,0.67,0.74,0.81\end{array}$ \\
\hline
\end{tabular}

\section{$2.3 \quad$ Heat Release Rate analysis}

The cylinder-charge bulk temperature evolution as well as the combustion heat release rate (HRR) have been estimated using an in-house thermodynamic model accounting for compression, wall heat losses, crevice volumes and piston rings blow-by. In the following, the processing steps and model settings are introduced.

First, the pressure trace from the piezo-electric sensor was pegged using the piezo-resistive sensor information. A offset has been added to the piezo-electric sensor read-out so that values from both pressure sensors agreed just before rapid compression was initiated. In the second step, the cylinder pressure trace has been filtered using a Savitzky-Golay filter with $3^{\text {rd }}$ order polynomial fitting. In the time interval $-0.2-0.3 \mathrm{~ms}$ from ID a filter frame length of 20 points $(0.2 \mathrm{~ms})$ has been selected so that the rapid HRR rise around ignition was not filtered out. Outside of this interval, a longer filter frame of 100 points $(1 \mathrm{~ms})$ was used in order to suppress the acoustic ringing in the cylinder. The filtered pressure trace and cylinder position trace were then given as an input to the HRR model.

Crevice model assuming the trapped gases temperature to adapt to cylinder wall temperature was used; the pistonring blow-by estimated by a labyrinth sealing model from [39]. The volume of crevices and piston-ring blow-by coefficients were estimated based on the design tolerances of the RCEM. Wall heat losses were estimated using a modified Woschni equation. Adaptations to the relation were needed considering the quiescent RCEM flow field and different piston speed evolution than in engines. Equation (1) describes the heat transfer coefficient $\alpha_{\mathrm{w}}$ model for the RCEM:

$\alpha_{w}=D^{-0.2} \cdot\left(\frac{P}{9.81 * 10^{4}}\right)^{0.8} \cdot T^{-0.53} \cdot\left(\left(C_{0}+C_{V o l} \cdot \frac{d V}{d t} \cdot \frac{4}{\pi \cdot D^{2}} \cdot\left(\frac{1}{\frac{V}{V_{H}}}\right)^{C_{H}}\right)+C_{2} \cdot \frac{V_{H} \cdot T_{1}}{V_{1} \cdot P_{1}} \cdot\left(P-P_{S}\right)\right)^{0.8}$

Here, $V$ describes the instantaneous RCEM cylinder volume, $V_{H}$ the displacement volume, $P$ the cylinder pressure (in $\mathrm{Pa}$ ) and $T$ is the bulk RCEM gas temperature. $D$ is the RCEM bore, and $V_{1}, P_{1}$, and $T_{1}$ describe the conditions in BDC prior to compression. The term $\left(P-P_{S}\right)$ is the difference in cylinder pressure between a compression stroke and actual reactive stroke and describes the increase of the wall heat losses due to combustion. This model includes the 
tuning constants $C_{0}, C_{V o l}$ and $C_{2}$ related to different contributions to the wall heat losses. Constant $C_{0}$ relates to the heat transfer from the quiescent hot bulk gas over the boundary layer to the cylinder walls. The term related to the $C_{V o l}$ accounts for the additional heat losses due to turbulence generated by the piston motion (wall shedding vortex) and the term related to $C_{2}$ describes the increase of heat losses due to combustion.

In order to reliably predict the HRR, the wall-heat loss model had to be tuned. Tuning constants $C_{0}$ and $C_{V o l}$ were adjusted based on the non-reactive compression stroke acquisitions so that the modeled HRR prediction without combustion was as close to zero as possible. In the next phase, the constant $C_{2}$ was tuned so that the HRR model accurately predicted the cumulative HRR in air (equal to the LHV of the pilot injection). Since no information was available on the heat losses in the dual-fuel cases the same value of $C_{2}$ has been used also in methane/air mixture.

The single-zone thermodynamic model for HRR calculation was used assuming stoichiometric conditions of the zone. Specific enthalpies were calculated using the ideal gas assumption. After the heat-loss model constants were determined, all experimental investigations were processed with the same model settings using automated routines.

\subsection{Definition of combustion metrics}

In order to compare the influence of different experimental parameters on the combustion HRR and transition from the pilot-fuel ignition to the premixed flame propagation, a set of HRR metrics had to be defined. These metrics were developed based on the characteristic shape of the HRR observed for all conditions. Here we focus primarily on the ignition behavior and transition between the pilot-fuel autoignition and premixed flame propagation. Throughout this time the flow field is governed by the pilot-jet induced turbulence. The premixed flame propagation is of secondary relevance since considerably different flame speeds are expected under the non-quiescent charge conditions found in engine applications.

Figure $3 a$ presents ensemble-averaged HRR curves for a variation of $\phi_{\mathrm{CH} 4}$. The diesel-case $\left(\phi_{\mathrm{CH} 4}=0\right) \mathrm{HRR}$ is characterized by two short peaks: first small peak was attributed to low-temperature reactivity, followed by a larger peak during the second-stage ignition propagation through the pilot-fuel cloud. After the peak, only a small HRR is observed as the last fuel-rich regions lean-out. In dual-fuel cases, the first stages of combustion proceed similarly as in the diesel-case - after the low-T reactivity distinct peak HRR occurred during the auto-ignition of the pilot-fuel and entrained methane. Higher peak HRR was observed for higher $\phi_{\mathrm{CH} 4}$. After the peak, a steep drop of HRR was observed and the HRR stabilized as a premixed flame has established. The rate of change in HRR during the premixed flame propagation was much slower than during the pilot-fuel combustion.

First, the high-temperature ignition delay (ID) was determined based on the HRR, by fitting a tangent to the HRR during the rapid rise at ignition. The interval between $20 \%$ and $80 \%$ of the peak HRR value (demonstrated in Figure 3b) was chosen to fit the tangent. The position on the time axis where this tangent crosses the abscissa was taken as the instant of the ignition. This procedure was found to be very robust, with low sensitivity of the detected ID to the selected thresholds of $20 \%$ and $80 \%$ for the tangent definition.

In the second step, the HRR curves were ensemble averaged over 10 experimental repetitions. To reduce the smearing of the curves due to the small cyclic fluctuations of the ID, the HRR curves were shifted in time for the difference between average and single-shot ID. Based on the characteristic HRR shape (Figure 3a), metrics of the HRR were derived as sketched in Figure 3b. The peak HRR was evaluated as well as the HRR after pilot-fuel burned (averaged over the interval $0.6-1.5 \mathrm{~ms}$ after peak HRR). Additionally, the pilot combustion duration and cumulative HRR were evaluated based on the curve fitting over the peak HRR interval (denoted in magenta on Figure 3b). The starting point of the interval was selected to be the ignition. Interval endpoint was determined as the time when HRR dropped below $20 \%$ of the difference between peak HRR and HRR after pilot burn. A functional form of the Wiebe function $\left(H R R \propto \frac{(m+1)}{t_{v}} \cdot\left(\frac{t}{t_{v}}\right)^{m} \cdot e^{-6.903 \cdot\left(t / t_{v}\right)^{m-1}}\right)$ was assumed - it can fit to various asymmetric bell-shaped peaks. Here, the $t_{v}$ describes the function duration, and the shape parameter $m_{v}$ determines the function shape, as demonstrated in Figure 3c. In the present work, the Wiebe function shape was fitted to the above-described time 
interval using MATLAB non-linear least squares fitting functionality. The function was found to well resemble the combustion HRR, both, with and without methane - a low uncertainty of the fitted parameters under all conditions can be reported. The highest uncertainty of the fit was in the value of $\mathrm{m}_{\mathrm{v}}$. This uncertainty propagates also into the less certain value of the curve width $t_{v}$. Nevertheless, the $95 \%$ probability interval width calculated by the fit function was less than $\pm 10 \%$ of the $t_{v}$ value under all investigated conditions. The HRR metrics were extracted from the fitted Wiebe parameters as shown in Figure $3 \mathrm{c}: \mathrm{t}_{\mathrm{v}}$ corresponds to the pilot combustion duration, and the area under the fitted curve as a metric for the cumulative HRR. The shape parameter $m$ determines the function shape and was not further analyzed as a metric by itself. The result of the fitting procedure is demonstrated in Figure $3 \mathrm{~b}$.

It is emphasized that the $t_{v}$ metric considerably exceeds any full-width at half-maximum Gaussian-deviation like metrics for combustion duration since it measures the time-interval from ignition until the fitted Wiebe function returns back to zero. Nevertheless, the so defined metrics enable a straightforward comparison over a wide range of conditions.

\section{Results}

\subsection{Influence of methane on the pilot-fuel ignition delay}

Ignition delays (ID) were determined based on tangent fitting to HRR as described in Section 2.4. Figure 4 presents the influence of premixed methane equivalence ratio $\left(\phi_{\mathrm{CH} 4}\right)$ on ID for a wide variation of experimental conditions: (a) variation of $\mathrm{T}_{\mathrm{SOI}}$, (b) variation of injection $\mathrm{ET}$, and (c) variation of charge oxygen content $\left[\mathrm{O}_{2}\right]$.

For all investigated conditions addition of methane was found to strongly defer the pilot fuel ignition. At all investigated $\mathrm{T}_{\mathrm{SOI}}$ and with constant injection parameters, a monotonous increase of ID for increasing $\phi_{\mathrm{CH} 4}$ has been detected, with nearly linear dependence on $\phi_{\mathrm{CH} 4}$ (Figure $4 \mathrm{a}$ ). In addition, both the absolute and relative ID sensitivity to $\phi_{\mathrm{CH} 4}$ increased at lower $\mathrm{T}_{\mathrm{SOI}}$. Up to $55 \%$ increased ignition delay was observed under the highest considered $\phi_{\mathrm{CH} 4}$. Similar influence has been reported before in RCEMs [19, 20, 24, 40] and optical engines [16]. Investigations in [24] showed that this is due to a chemical interaction of methane inhibiting the low- $\mathrm{T}$ ignition in the lean pilot-fuel mixtures. Other methane influences like the change of $\mathrm{T}_{\mathrm{SOI}}$ due to changed specific heat ratio, and lower oxygen concentration due to the dilution of air with methane, were shown to be negligible in comparison to the methane chemical effect.

Figure $4 \mathrm{~b}$ presents the dependence of ID on pilot injector $\mathrm{ET}$ and $\phi_{\mathrm{CH} 4}$ at $\mathrm{T}_{\mathrm{SOI}}=850 \mathrm{~K}$. Additional measurements with ET of 700 and $1000 \mu$ s from [20] were added to include cases with the ignition delay shorter than injection duration (negative ignition dwell time). A coherent trend of shorter injections exhibiting a shorter ignition delay was observed independently of methane concentration. The diesel-case ET $=300 \mu$ s injection at $p_{\text {inj }}=1000$ bar showed $150 \mu \mathrm{s}(17 \%)$ shorter ignition delay than the longer injections at $\mathrm{p}_{\mathrm{inj}}=600 \mathrm{bar}$. When increasing the injection duration beyond $\mathrm{ET}=500 \mu$ s (ignition dwell approximately zero) no additional dependence of ID on the injection ET was observed. This indicates that this effect of shorter ID for shorter injections is driven by the end of injection entrainment wave [41] as already observed before in an optical engine by Malbec et al. [42]. In the present work, this effect is less pronounced than in [42]. For very short injections, on the other hand, a longer ignition delay would be expected due to the reduced reactivity of the available mixture, potentially also leading to misfire [43]. No such behavior has been observed in the present investigations even at $\mathrm{T}_{\mathrm{SOI}}=770 \mathrm{~K}$ conditions and highest considered $\phi_{\mathrm{CH} 4}$ (not shown here). This indicates that within the ignition delay range of $0.7-2.0 \mathrm{~ms}$ detected in this study the pilotfuel concentration does not drop sufficiently to reach the misfire regime.

Finally, the combined influence of charge oxygen content $\left[\mathrm{O}_{2}\right]$ and $\phi_{\mathrm{CH} 4}$ on the ID has been investigated at $\mathrm{T}_{\mathrm{SOI}}$ of $810 \mathrm{~K}$ and $850 \mathrm{~K}$ (Figure 4c). Same concentrations of methane in the charge as for the $21 \%$ oxygen cases have been considered, leading to higher values of $\phi_{\mathrm{CH} 4}$ in the reduced $\left[\mathrm{O}_{2}\right]$ cases. About $30 \%$ increased ID at $\phi_{\mathrm{CH} 4}=0$ was measured at $15 \%\left[\mathrm{O}_{2}\right]$ comparing to the $21 \%\left[\mathrm{O}_{2}\right]$ cases, in good agreement with the relation ID $\propto[\mathrm{O} 2]^{-1}$ from [44]. 
In methane-containing charge, a lower sensitivity of ID to methane was detected than at $21 \%\left[\mathrm{O}_{2}\right]$, resulting in an only moderate increase of ID in dual-fuel cases when reducing the ID. The relation ID $\propto[\mathrm{O} 2]^{-1}$ from [44] overpredicts the oxygen concentration effect on ID in dual-fuel cases.

\subsection{Dependence of HRR on the pilot injection and charge conditions}

Having demonstrated large influence of methane on ignition delay, in this section, we investigate the influence of methane concentration, injection parameters, and charge conditions on the HRR metrics: $t_{v}$, peak HRR, and cumulative HRR. Figure 5 presents the dependence of HRR metrics on the $\mathrm{T}_{\mathrm{SOI}}$ and $\phi_{\mathrm{CH} 4}$. A considerable increase in $t_{v}$ was observed under dual-fuel conditions. Whereas in the diesel-cases similar value of $t_{v}$ was observed for all $T_{S O I}$, a larger prolongation of the $t_{v}$ with $\phi_{\mathrm{CH} 4}$ was measured for the colder charge conditions. The addition of methane increases the peak-HRR with, again, a stronger influence at lower $\mathrm{T}_{\mathrm{SOI}}$. Overall, in diesel-case, the cumulative HRR correlates well with the pilot-fuel LHV. With increasing $\phi_{\mathrm{CH} 4}$, a considerable increase of the cumulative HRR was observed: up to 5 times at $\phi_{\mathrm{CH} 4}=0.66, \mathrm{~T}_{\mathrm{SOI}}=770 \mathrm{~K}$. This indicates the considerable contribution of entrained methane combustion to the total heat released during the transition and suggests the existence of regions with leanmixture within the pilot-fuel spray cloud at the time of ignition. At higher $\mathrm{T}_{\mathrm{SO}}$ less of the entrained methane is combusted as explained by the shorter ID leading to pilot-fuel richer conditions at ignition.

Figure 6 shows the dependence of HRR metrics on the injection ET, $\mathrm{p}_{\mathrm{inj}}$, and $\phi_{\mathrm{CH} 4}$ at $\mathrm{T}_{\mathrm{SOI}}=810 \mathrm{~K}$. For all pilot injections, prolonged duration $t_{v}$ was observed with higher $\phi_{\mathrm{CH} 4}$. The higher $p_{\text {inj }}$ case $\left(p_{\text {inj }}=1000\right.$ bar, ET $\left.=300 \mu \mathrm{s}\right)$ showed the highest sensitivity to methane, whereas all injections at $p_{i n j}=600$ bar resulted in a comparable increase of $\mathrm{t}_{\mathrm{v}}$ with increasing $\phi_{\mathrm{CH} 4}$. Observing the peak HRR metric, a clear dependence of the peak-HRR on the injected pilotfuel mass (related to the ET) is visible. The results of the medium injection duration case (ET $=400 \mu \mathrm{s})$ and higher $p_{\text {inj }}$ case $\left(p_{\text {inj }}=1000\right.$ bar) having a similar mass of the injected pilot-fuel and very similar peak-HRR evolution thereby confirming this statement. For all injection variations, a comparable sensitivity of the peak-HRR to $\phi_{\mathrm{CH} 4}$ was observed. Similarly to the dependence of peak-HRR on the injected mass, such dependence has been also detected in the cumulative HRR metric. Nevertheless, the curve for the ET $=400 \mu$ s injection is less steep than for the shorter $p_{\text {inj }}=1000$ bar injection with similar injected mass. This was attributed to faster entrainment of methane at higher injection pressure.

Last, we investigate the influence of reduced charge oxygen content $\left[\mathrm{O}_{2}\right]$ and variable $\phi_{\mathrm{CH} 4}$ on the HRR metrics at $\mathrm{T}_{\text {SOI }}$ of $810 \mathrm{~K}$ as well as at $850 \mathrm{~K}$ to compensate for the $\left[\mathrm{O}_{2}\right]$ effect on ID (Figure 7). A very strong prolongation of $\mathrm{t}_{\mathrm{v}}$ has been recognized with reduced $\left[\mathrm{O}_{2}\right]$ and high $\phi_{\mathrm{CH} 4}$ regardless of the ID and $\mathrm{T}_{\mathrm{SOI}}$. This indicates a strong reduction of the overall reactivity in the cases combining methane and reduced $\left[\mathrm{O}_{2}\right]$. In a comparison of $\mathrm{T}_{\mathrm{SOI}}=810 \mathrm{~K}$ case at $21 \%\left[\mathrm{O}_{2}\right]$ and $850 \mathrm{~K}$ case at $15 \%$ [O2], the colder $21 \%$ [O2] case shows a considerably shorter $\mathrm{t}_{\mathrm{v}}$ at comparable ID (Figure 5a). This increase of the $\mathrm{t}_{\mathrm{v}}$ at reduced $\left[\mathrm{O}_{2}\right]$ exhibits itself also in a remarkably reduced peak HRR. At $\phi_{\mathrm{CH} 4}=0$, around $30 \%$ reduced peak HRR is observed at $15 \%\left[\mathrm{O}_{2}\right]$, as also expected from studies of EGR in diesel combustion [45]. Whereas for all $21 \%\left[\mathrm{O}_{2}\right]$ cases a clear trend of higher peak HRR with increasing $\phi_{\mathrm{CH} 4}$ has been observed, this trend is less pronounced for the $18 \%\left[\mathrm{O}_{2}\right]$ cases and even inverted in the $15 \%\left[\mathrm{O}_{2}\right]$ cases. In terms of the cumulative HRR, a lower value of this metric has been recognized with reducing $\mathrm{O}_{2}$. Nevertheless, the trend of increasing cumulative HRR is present even in the $15 \%\left[\mathrm{O}_{2}\right]$ case, though less pronounced. Oxygen appears not to be the reactant limiting the peak-HRR. This indicates a chemical effect of combined methane and reduced $\left[\mathrm{O}_{2}\right]$ content, increasing $t_{v}$ and decreasing peak-HRR.

\subsection{Pilot-fuel mixing state evolution}

To better understand the above-observed trends, the information on spray boundary conditions like the pilot-fuel mixture evolution and spray volume is of high value. For this purpose, non-reactive tracer-PLIF investigations described in detail in Appendix A were performed to characterize the pilot-spray mixing evolution and fueldistribution. The results of these investigations are shown below: Figure 8 draws the temporal evolution of maximal and mass-median (half of the pilot-fuel mass at higher $\phi$ ) dodecane/air equivalence ratio $\left(\phi_{\mathrm{C} 12}\right)$ extracted from 10 
experimental repetitions at all considered injection pressures and ET. The liquid part of the spray has been removed from the images since quantification of the equivalence ratio in the liquid phase is not possible. Even outside the liquid spray, very high maximal $\phi_{\mathrm{C} 12}$ was detected. After the end of injection (EOI), maximal and mass-median $\phi_{\mathrm{C} 12}$ rapidly decrease. Longer pilot-injections show a longer persistence of the rich-zones as expected due to later EOI. Throughout the cycle, the value of maximal $\phi_{\mathrm{C} 12}$ is approximately a factor 2 higher than the mass-median value. It is interesting to note that both $\mathrm{ET}=300 \mu$ s injections (at 600 bar or 1000 bar injection pressure) show a very similar evolution of both maximal and mass-median $\phi_{\mathrm{C} 12}$, despite a factor 2 difference in the injected mass.

Besides the mean pilot-fuel equivalence ratio, the fuel-jet volume and average pilot-fuel density (pilot-fuel mass divided by the spray volume) were selected as the meaningful values describing the pilot-fuel jet state, and were used to investigate correlations of pilot-fuel mixing state to the HRR metrics shown in the section "Discussion". The volume of the spray was derived from the processed Schlieren images under an assumption of spray axial symmetry. Figure 9 presents the evolution of pilot-spray plume volume and averaged fuel density for all considered pilot injections.

The high-pressure injection initiates the highest spray-volume, followed by the injections at $p_{\text {inj }}=600$ bar in the order of decreasing ET. Rather low influence of ET at $p_{\text {inj }}=600$ bar up to $1.4 \mathrm{~ms}$ aSOI has been observed. Similar predictions are calculated also by 1-D spray models, which suggest no deviation of spray penetration from penetration of an infinite injection case, up to twice the injection duration [41]. Overall, this leads to considerable influence of injection duration on the average fuel-density, with longer injections leading to a higher fuel density (Figure 9). In the terms of fuel-density, the 1000 bar injection lies between the $300 \mu \mathrm{s}$ and $400 \mu$ s ET injections at $\mathrm{p}_{\mathrm{inj}}=600$ bar. The tracer-PLIF investigations confirm a similar evolution of the median equivalence ratio as predicted by the schlieren-based fuel-density estimation (Figure 8, right).

\section{Discussion}

Results show that combustion parameters like $\mathrm{T}_{\mathrm{SOI}}, \phi_{\mathrm{CH} 4}$, injector $\mathrm{ET}, \mathrm{p}_{\mathrm{inj}}$ and $\left[\mathrm{O}_{2}\right]$ strongly influence the HRR metrics $t_{v}$ and peak-HRR. Furthermore, these parameters simultaneously influence boundary conditions like ID, flow field at ignition, and pilot-fuel mixing. Thus, identifying the governing processes is challenging. However, several mechanisms have been identified as major drivers influencing the transition:

- Chemical influence of methane changing the pilot-fuel mixture reactivity

- Injection-induced turbulence and its decay

- Pilot-fuel mixing state at ignition, related to the pilot-fuel reactivity at this state

- Diffusion-combustion at the interface between the fuel-rich burnt pilot-fuel-jet and surrounding charge

- Availability of oxygen in the pilot-jet

The discussion attempts to corroborate the results from complete experimental matrix in order to identify the firstorder influences on dual-fuel combustion during the transition from ignition to established premixed flame outside the pilot-jet. The HRR metrics of the whole measurement matrix were correlated to parameters like ignition delay, pilot-fuel mixing field, or pilot-fuel stratification. The analysis of influences in the cases with reduced oxygen content is presented separately.

\subsection{HRR metrics correlation to the ignition delay}

The ID of pilot-fuel is often seen as a measure of reactivity and depends on both, $\mathrm{T}_{\mathrm{SOI}}$ and $\phi_{\mathrm{CH} 4}$, as discussed in Section 3.1. Figure 10 presents the correlation of the HRR metrics $t_{v}$ and peak-HRR to the pilot-fuel ID with the aim to investigate the coupling between global 'highest reactivity' (represented by the ID) and overall mixture reactivity represented by the $t_{v}$ or peak-HRR. 
A consistent trend of increasing duration of pilot-fuel combustion $\mathrm{t}_{\mathrm{v}}$ with the increasing ID is visible in Figure 10 left. Nevertheless, significant differences among diesel and dual-fuel cases, and among the cases with different injection parameters have been observed. The diesel-cases show a rather short ID as well as $t_{v}$ independent of the $\mathrm{T}_{\mathrm{SOI}}$. Exceptions are the $\mathrm{ET}=300 \mu \mathrm{s}$ injections at $\mathrm{T}_{\mathrm{SOI}}=770 \mathrm{~K}$, representing the least-reactive diesel-cases of the matrix, showing longer $t_{v}$. In dual-fuel cases, the $t_{v}$ is more sensitive to $\phi_{\mathrm{CH} 4}$ than to ID. Starting the analysis at $770 \mathrm{~K}$ $T_{\text {SOI }}$ : a considerable decrease of the $t_{v}$ with increasing injection duration has been observed. Nevertheless, a similar absolute sensitivity of $t_{v}$ on ID (and $\phi_{\mathrm{CH} 4}$ ) has been observed for all points at $p_{\text {inj }}=600$ bar. A higher sensitivity has been observed for the $p_{i n j}=1000$ bar injection. The faster pilot-fuel combustion for longer injections is explained mostly by the fuel-richer conditions available at the time of ignition. The increased sensitivity of $t_{v}$ to $\phi_{\mathrm{CH} 4}$ at $\mathrm{p}_{\mathrm{inj}}=1000$ bar cannot be directly explained by this argument. This will be further discussed in Sections 4.2 and 4.3. By increasing the $\mathrm{T}_{\mathrm{SO}}$, the differences among different injection-duration cases diminish and the influence of ET on the $t_{v}$ becomes ambiguous: $t_{v}$ of the $E T=500 \mu$ injection becomes longer than for the shorter injections at $\mathrm{T}_{\mathrm{SOI}}=850 \mathrm{~K}$. This is explained here by the considerable portion of pilot-fuel located in fuel-rich zones: the diffusion combustion at the stoichiometric contour leads to HRR after the pilot-fuel has burnt. In general, $t_{v}$ appears to be only weakly coupled to the ID in the dual-fuel cases - a significantly stronger influence of $\phi_{\mathrm{CH} 4}$ on $t_{\mathrm{v}}$ has been observed.

Investigating the correlation of peak-HRR to the ID (Figure 10 right), a general tendency of higher peak-HRR with increased $\mathrm{T}_{\mathrm{SOI}}$ and in cases with higher injected pilot-fuel mass was observed. The influence of pilot-fuel mass is straightforward: a larger amount of combustible mixture available at the time of ignition as well as larger spray volume at ignition lead to higher peak-HRR values. Methane effect on ID explains the trend of higher peak-HRR with increasing the $\mathrm{T}_{\mathrm{SOI}}$ : to maintain the ID with increasing $\phi_{\mathrm{CH} 4}$ the $\mathrm{T}_{\mathrm{SOI}}$ has to be increased. Therefore, additional methane is mixed into the pilot-fuel at an otherwise unchanged pilot-fuel mixture - this leads to higher peak-HRR. The pilot injection-pressure influence is interesting: High-pressure injection admits a comparable pilot-fuel mass as the $\mathrm{ET}=400 \mu \mathrm{s}$ injection at $\mathrm{p}_{\mathrm{inj}}=600$ bar. Nevertheless, at $\mathrm{T}_{\mathrm{SOI}}=770 \mathrm{~K}$, in comparison to the $\mathrm{ET}=400 \mu \mathrm{s}$ injection, a significantly lower peak-HRR is observed at $p_{i n j}=1000$ bar. Considering $t_{v}$ prolonged by a factor of 2 , this is expected due to the overall comparable available energy within the pilot-fuel jet. Contrary, at higher $\mathrm{T}_{\mathrm{SOI}}$, the highpressure injection shows the highest peak-HRR. This is explained by the oxygen availability limiting the peak-HRR in cases with longer ET and low injection pressure.

Apart from the increased $t_{v}$ along with decreased peak-HRR at low $\mathrm{T}_{\mathrm{SOI}}$ dual-fuel cases, no other indication of leanout or misfire has been observed: in all cases, the peak-HRR increased with the addition of methane regardless of the longer ID and prolonged $t_{v}$.

\subsection{HRR metrics correlation to the pilot-fuel mixing field}

Tracer-PLIF data (Section 3.3 and Appendix A) providing information on the mixing field of pilot-fuel at the time of ignition was used to understand the influence of pilot-fuel mixing on combustion metrics. The correlations of $t_{v}$ and peak-HRR in regard to the mass-median $\phi_{\mathrm{C} 12}$ are presented in Figure 11.

A clear tendency of extended $t_{\mathrm{v}}$ under leaner pilot-fuel conditions (lower mass-median $\phi_{\mathrm{C} 12}$ ) is visible from Figure 11 (left). In the diesel-cases (empty systems), a minimum of $\mathrm{t}_{\mathrm{v}}$ is apparent at mass-median $\phi_{\mathrm{C} 12}$ around stoichiometry. Longer transition time in leaner cases can be attributed to the large portion of fuel-mass located under lean conditions, under which the mixture is less reactive. The dual-fuel cases follow a similar trend of a longer $t_{v}$ with leaner $\phi_{\mathrm{C} 12}$ as in the diesel-cases - confirming the strong influence of pilot-fuel mixing state on the combustion transition. Generally, with increasing $\phi_{\mathrm{CH} 4}$, a longer $t_{\mathrm{v}}$ at same $\phi_{\mathrm{C} 12}$ has been observed. This was expected due to the chemical influence of methane on the autoignition of lean $\phi_{\mathrm{C} 12}[24]$.

The correlation of peak-HRR to $\phi_{\mathrm{C} 12}$ shows a strong influence of both, $\phi_{\mathrm{C} 12}$ and pilot-injection strategy, on the peakHRR (Figure 11 right). Investigating the diesel-cases first, we see a higher peak-HRR with higher $\phi_{\mathrm{C} 12}$, which is primarily the influence of a positive correlation between mean $\phi_{\mathrm{C} 12}$ and pilot-fuel mass injected. Additionally, especially at low $\mathrm{T}_{\mathrm{SOI}}$, the higher reactivity of richer $\phi_{\mathrm{C} 12}$ mixture contributes to the increasing peak-HRR. Dual-fuel 
cases using same pilot-injection settings show a clear correlation of peak-HRR to the $\phi_{\mathrm{C} 12}$ at ignition: an almost linear increase of the peak-HRR with decreasing $\phi_{\mathrm{C} 12}$ has been observed regardless of the $\mathrm{T}_{\mathrm{SOI}}$ and $\phi_{\mathrm{CH} 4}$. This is demonstrated by fitted lines on Figure 11b. Only the diesel-cases and the cases with very long ID show a deviation from this behavior. A larger amount of entrained methane can be combusted at decreased $\phi_{\mathrm{C} 12}$ (same pilot-fuel mass) due to the overall decreased total equivalence ratio. Considering the moderate influence of $\mathrm{CH}_{4}$ on $\mathrm{t}_{v}$, a higher quantity of entrained methane is evident in higher peak-HRR. The same trend has been observed also for the high $\mathrm{p}_{\text {inj }}$ case. Nevertheless, lower peak-HRR values than for the ET $=400 \mu$ sase have been observed at same $\phi_{\mathrm{C} 12}$ despite the comparable injected mass. The stratification and local distribution of the pilot-fuel within the spray might be responsible for the observed differences.

To investigate this effect of local fuel distribution, the correlation of $t_{v}$ and peak-HRR to the spray-plume volume at the time of ignition, as a measure of fuel stratification, is presented in Figure 12. Similarly as observed in the correlations of $t_{v}$ and $\phi_{C 12}$ a weak correlation between increasing $t_{v}$ with increasing pilot-spray plume volume has been observed. Only the short $\mathrm{T}_{\mathrm{SOI}}=770 \mathrm{~K}$ injections are clear outliers and have already been identified above to be on the edge of leaning-out.

Correlation of peak-HRR and jet-volume shows clear upper-bound of peak-HRR also marked by the straight line (Figure 13 right). Oxygen appears to be the limiting reactant on this upper line and the overall reactivity of the mixture plays a minor role. Only the short $\mathrm{T}_{\mathrm{SOI}}=770 \mathrm{~K}$ points and some diesel cases considerably deviate from this upper bound. These deviating points were already identified to be close to lean-out indicating very lean conditions at ignition, where the oxygen-limit does not apply anymore.

\subsection{Influence of reduced charge oxygen content}

Reduced oxygen content cases simulate reduced charge reactivity as achieved with use of EGR in real engines. Considerably prolonged ignition delay, prolonged $t_{v}$, and reduced peak HRR have been shown in Sections 3.1 and 3.2. Figure 13 shows the dependence of $t_{v}$ and peak-HRR on the ignition delay for a variation of $\left[\mathrm{O}_{2}\right]$ and $\mathrm{T}_{\mathrm{SOI}}$. The aim of this variation is to distinguish the influence of reduced $\left[\mathrm{O}_{2}\right]$ on ignition delay and mixture reactivity after the ignition.

Correlation of $\mathrm{t}_{\mathrm{v}}$ and ID again shows a very strong decreased $\left[\mathrm{O}_{2}\right]$ influence significantly reducing the mixture reactivity (Figure $13 \mathrm{left}$ ). $\mathrm{T}_{\mathrm{SOI}}$ of $810 \mathrm{~K}$ and $850 \mathrm{~K}$ for injection setting $\mathrm{ET}=400 \mu \mathrm{s}$ and $\mathrm{p}_{\mathrm{inj}}=600 \mathrm{bar}$ were considered. Comparing the $15 \%\left[\mathrm{O}_{2}\right]$ case at $\mathrm{T}_{\mathrm{SOI}}=850 \mathrm{~K}$ to the $21 \%\left[\mathrm{O}_{2}\right]$ case at both $\mathrm{T}_{\mathrm{SOI}}=770 \mathrm{~K}$ and $810 \mathrm{~K}$ the strong influence of oxygen content is visible: while the ID and injector ET are comparable, by a factor of 2 higher values of $t_{v}$ were detected despite the higher $T_{\mathrm{SOI}}$. This shows a considerable reduction of chemical reactivity in combined methane and reduced $\left[\mathrm{O}_{2}\right]$ cases. This influence is significantly less pronounced in the $18 \%\left[\mathrm{O}_{2}\right]$ cases. Comparing the $\mathrm{T}_{\mathrm{SOI}}=810 \mathrm{~K}$ and $\mathrm{T}_{\mathrm{SOI}}=850 \mathrm{~K}$ cases, shorter $\mathrm{t}_{\mathrm{v}}$ values were observed at lower $\mathrm{T}_{\mathrm{SOI}}$. A possible explanation is the overall very rich mixture due to to the shorter ID at $850 \mathrm{~K}$ ( $\phi_{\mathrm{CH} 4}$ up to 0.8 with reduced $\left[\mathrm{O}_{2}\right]$ results in high overall equivalence ratio).

This strong influence of $\left[\mathrm{O}_{2}\right]$ on $\mathrm{t}_{\mathrm{v}}$ exhibits itself also in the decreased peak-HRR (Figure 13 right). Again a considerably higher influence of $\left[\mathrm{O}_{2}\right]$ on peak-HRR than on ID is observed, especially pronounced at $15 \%\left[\mathrm{O}_{2}\right]$ case. The decreased influence of $\phi_{\mathrm{CH} 4}$ is partially attributed to oxygen being the limiting reactant. Nevertheless, this can lead to only up to a peak-HRR decrease proportionally corresponding to the $\left[\mathrm{O}_{2}\right]$ reduction. However, the observed reduction is significantly higher. This indicates the chemical influence of methane under reduced $\left[\mathrm{O}_{2}\right]$ to be the dominant effect decreasing the peak-HRR.

\section{Summary and conclusions}

Combustion of pilot-fuel in a compressed methane/air mixture was investigated in a rapid compression-expansion machine (RCEM), analogous to the combustion transition process from ignition until established premixed flame in 
pilot-ignited lean natural gas engines. The aim was to understand the influence of operation parameters on pilot-fuel burning: methane/air equivalence ratio, charge temperature, and oxygen content, as well as pilot-injection strategy, were varied. The quiescent flow field in the RCEM enabled studying of the pilot-fuel burning without the heat release rate (HRR) being masked by rapid premixed flame spreading. HRR analysis was supplemented with nonreactive Schlieren and tracer-PLIF optical data of the pilot-fuel spray penetration and average pilot-fuel mixture fraction. HRR metrics like pilot-fuel combustion duration $t_{v}$ and peak-HRR were determined. Correlations of different combustion metrics to the pilot-fuel injection and charge properties were investigated, in order to derive conclusions regarding the major influences on the transition from pilot-ignition to premixed flame propagation in pilot-ignited lean-premixed CNG engines.

10 Based on the analysis of experimental results the following conclusions can be stated:

1. Increasing methane amount leads to a longer pilot-fuel ignition delay. Higher absolute and relative sensitivity to methane has been observed at lower $\mathrm{T}_{\mathrm{SOI}}$ and/or at reduced charge $\left[\mathrm{O}_{2}\right]$.

2. Pilot-injection parameters were found to have a small influence (up to $10 \%$ ) on the ignition delay (ID) both, in the diesel and dual-fuel cases. Nevertheless, a consistent trend of shorter injections having shorter ignition delay was found and attributed to the end of injection entrainment wave influence in line with previous investigations in optical engines [42].

3. In the diesel-cases shortest pilot combustion duration $\mathrm{t}_{\mathrm{v}}$ was detected for cases with median pilot-fuel equivalence ratio $\left(\phi_{\mathrm{C} 12}\right)$ at ignition around stoichiometry. Slower combustion at leaner conditions was attributed to the reduced mixture reactivity, and at fuel-richer conditions to the high contribution of pilot-fuelmixing-governed diffusion combustion.

4. Methane was found to moderately increase pilot-fuel burning time $t_{\mathrm{v}}$. Generally, at the same mixing state of pilot-fuel at ignition, the cases with higher $\phi_{\mathrm{CH} 4}$ were found to have a higher value of $t_{\mathrm{v}}$. This trend has been attributed to the chemical influence of methane reducing the pilot-fuel reactivity. Furthermore, at otherwise unchanged charge conditions the influence of methane prolonging the ID reduces the pilot-fuel equivalence ratio at ignition. This leads to the overall lower reactivity of the mixture at ignition, thus increasing the $t_{v}$.

5. Pilot-fuel injection strategy influences the peak-HRR. Particularly in dual-fuel cases, a clear oxygenavailability limit on the peak-HRR was observed: the peak-HRR for most dual-fuel cases (except close to lean-out) was proportional to the initiated spray volume at ignition. Lack of variation from this proportionality indicates oxygen to be the limiting reactant in combustion.

6. With increasing $\phi_{\mathrm{CH} 4}$ a very strong increase of the peak-HRR has been observed and attributed to simultaneous combustion of methane entrained in the pilot-spray volume. This trend was consistent for the whole experimental matrix except in cases with reduced $\left[\mathrm{O}_{2}\right]$ representing EGR.

7. The influences of reduced $\left[\mathrm{O}_{2}\right]$ on the ignition delay and the combustion duration $\mathrm{t}_{\mathrm{v}}$ were found to be strong. At constant ID, in dual-fuel cases, up to 2 times longer $t_{v}$ has been observed at $15 \%\left[\mathrm{O}_{2}\right]$, compared to the $21 \%\left[\mathrm{O}_{2}\right]$ cases with similar ignition delay and lower $\mathrm{T}_{\mathrm{SOI}}$. This effect is probably due to the amplified chemical influence of methane under reduced $\left[\mathrm{O}_{2}\right]$ conditions leading to a further reduction of the mixture reactivity.

8. The combined retarding effect of methane and reduced $\left[\mathrm{O}_{2}\right]$ on $\mathrm{t}_{\mathrm{v}}$ exhibits itself in decreasing peak-HRR with increasing $\phi_{\mathrm{CH} 4}$. A factor of 3-4 lower peak-HRR values at $15 \%\left[\mathrm{O}_{2}\right]$, compared to the cases with $21 \%\left[\mathrm{O}_{2}\right]$ at comparable ignition delay, indicate that this is not the effect of oxygen-availability limitation as reported for the $21 \%\left[\mathrm{O}_{2}\right]$ cases.

The findings about the transition behavior of the dual-fuel combustion based on HRR analysis in combination with the experimentally investigated mixture state of the pilot-fuel reveal a first insight into the involved processes. In particular, the mixture reactivity has been identified to be an essential parameter during the combustion mode transition. To gain a further understanding of the interaction of auto-ignition and turbulent mixing (stratification, local distribution), in Part 2 of this study, an advanced set of optical diagnostics $\left(\mathrm{CH}_{2} \mathrm{O}-\mathrm{PLIF} \mathrm{OH}^{*}\right.$ chemiluminescence, and Schlieren imaging) has been applied to study the combustion transition. Furthermore, the 
experimental results are underlined and corroborated with numerical calculations (homogenous reactor model as well as simulations of the laminar flame speed) of various methane/dodecane/air mixtures. This enables a further discussion regarding the influence of methane on the chemical and/or physical driven sub-processes governing the dual-fuel combustion transition.

Table 3: Summary of the observed influences of charge and injection parameters on pilot-fuel combustion metrics: ID, $t_{v}$ and peak-HRR. Symbol interpretation: Arrow direction - increasing or decreasing influence. Number of arrows (1 up to 3) - effect strength.

\begin{tabular}{|c|c|c|c|}
\hline Parameter/Influence & Ignition Delay & $\begin{array}{c}\text { Pilot-fuel combustion } \\
\text { duration } t_{v}\end{array}$ & Peak-HRR \\
\hline$\phi_{\mathrm{CH} 4}$ & $\pi \lambda$ & $\begin{array}{c}\boldsymbol{\nearrow} \\
(\nearrow \nearrow \nearrow \text { when combined } \\
\left.\text { with reduced }\left[\mathrm{O}_{2}\right]\right)\end{array}$ & $\begin{array}{c}\nearrow \nearrow \nearrow \\
\text { Reduced influence at high } \\
\mathrm{T}_{\mathrm{SOI}} \text {, or close to misfire } \\
\text { (short ET, low } \mathrm{T}_{\mathrm{SOI}} \text { ) } \\
\end{array}$ \\
\hline $\mathbf{T}_{\text {SOI }}$ & $y$ & $\rightarrow$ & $\begin{array}{c}\text { Less time for entrainment } \\
\text { of methane }\end{array}$ \\
\hline $\begin{array}{l}\text { EGR: } \\
\text { Decreasing charge }\left[\mathrm{O}_{2}\right]\end{array}$ & $\pi$ & $\begin{array}{c}\nearrow \nearrow \nearrow\left(\nearrow \text { at } \phi_{\mathrm{CH} 4}=0\right) \\
\text { Amplified by the effect of } \\
\text { methane }\end{array}$ & $\begin{array}{c}>\searrow\left(\searrow \text { at } \phi_{\mathrm{CH} 4}=0\right) \\
\text { Strongly reduced mixture } \\
\text { reactivity }\end{array}$ \\
\hline Pilot injection $\left(E T / \mathbf{p}_{\mathrm{inj}}\right)$ & $\begin{array}{c}\nearrow\left(\downarrow \text { with } \mathbf{p}_{\text {inj }} \uparrow\right) \\
\text { Shorter ET and high } p_{\text {inj }} \\
\text { lead to shorter ID }\end{array}$ & $\begin{array}{c}\rightarrow \\
\text { (Except: very long ET } \\
\text { leads to diffusion } \\
\text { combustion and longer } t_{v} \text { ) }\end{array}$ & $\pi \pi$ \\
\hline
\end{tabular}

\section{Acknowledgements:}

Financial support from the Competence Center for Energy and Mobility (CCEM, project "ScheDual") and the Swiss Federal Office of Energy (grant SI/501123-01) is gratefully acknowledged.

\section{References}

1. Yang, B., Xi, C., Wei, X., Zeng, K., et al., "Parametric Investigation of Natural Gas Port Injection and Diesel Pilot Injection on the Combustion and Emissions of a Turbocharged Common Rail Dual-Fuel Engine at Low Load." Applied Energy, 2015. 143(Supplement C): p. 130-137, doi: http://dx.doi.org/10.1016/j.apenergy.2015.01.037.

2. Liu, J., Yang, F., Wang, H., Ouyang, M., et al., "Effects of Pilot Fuel Quantity on the Emissions Characteristics of a Cng/Diesel Dual Fuel Engine with Optimized Pilot Injection Timing." Applied Energy, 2013. 110(Supplement C): p. 201-206, doi: http://dx.doi.org/10.1016/j.apenergy.2013.03.024.

3. Zhou, L., Liu, Y.-F., Wu, C.-B., Sun, L., et al., "Effect of the Diesel Injection Timing and the Pilot Quantity on the Combustion Characteristics and the Fine-Particle Emissions in a Micro-Diesel Pilot-Ignited Natural-Gas Engine." Proceedings of the Institution of Mechanical Engineers, Part D: Journal of Automobile Engineering, 2013. 227(8): p. 1142-1152, doi: http://dx.doi.org/10.1177/0954407013480452.

4. Magno, A., Mancaruso, E., and Vaglieco, B.M. "Combustion Analysis of Dual Fuel Operation in Single Cylinder Research Engine Fuelled with Methane and Diesel". 2015. SAE Technical Paper 2015-24-2461, doi: http://dx.doi.org/10.4271/2015-24-2461.

5. Abdelaal, M.M. and Hegab, A.H., "Combustion and Emission Characteristics of a Natural Gas-Fueled Diesel Engine with Egr." Energy Conversion and Management, 2012. 64: p. 301-312, doi: http://dx.doi.org/10.1016/j.enconman.2012.05.021.

$6 . \quad$ Sun, L., Liu, Y., Zeng, K., Yang, R., et al., "Combustion Performance and Stability of a Dual-Fuel Diesel-Natural-Gas Engine." Proceedings of the Institution of Mechanical Engineers, Part D: Journal of Automobile Engineering, 2014. 229(2): p. 235-246, doi: http://dx.doi.org/10.1177/0954407014537814.

7. Papagiannakis, R.G. and Hountalas, D.T., "Experimental Investigation Concerning the Effect of Natural Gas Percentage on Performance and Emissions of a Di Dual Fuel Diesel Engine." Applied Thermal Engineering, 2003. 23(3): p. 353365, doi: http://dx.doi.org/10.1016/S1359-4311(02)00187-4. 
8. Papagiannakis, R.G. and Hountalas, D.T., "Combustion and Exhaust Emission Characteristics of a Dual Fuel Compression Ignition Engine Operated with Pilot Diesel Fuel and Natural Gas." Energy Conversion and Management, 2004. 45(18): p. 2971-2987, doi: http://dx.doi.org/10.1016/j.enconman.2004.01.013.

9. Lounici, M.S., Loubar, K., Tarabet, L., Balistrou, M., et al., "Towards Improvement of Natural Gas-Diesel Dual Fuel Mode: An Experimental Investigation on Performance and Exhaust Emissions." Energy, 2014. 64(Supplement C): p. 200-211, doi: http://dx.doi.org/10.1016/j.energy.2013.10.091.

10. Abd Alla, G.H., Soliman, H.A., Badr, O.A., and Abd Rabbo, M.F., "Effect of Pilot Fuel Quantity on the Performance of a Dual Fuel Engine." Energy Conversion and Management, 2000. 41(6): p. 559-572, doi: http://dx.doi.org/10.1016/S0196-8904(99)00124-7.

11. Abd Alla, G.H., Soliman, H.A., Badr, O.A., and Abd Rabbo, M.F., "Effect of Injection Timing on the Performance of a Dual Fuel Engine." Energy Conversion and Management, 2002. 43(2): p. 269-277, doi: http://dx.doi.org/10.1016/S0196-8904(00)00168-0.

12. Nithyanandan, K., Gao, Y., Wu, H., Lee, C.-F., et al., "An Optical Investigation of Multiple Diesel Injections in Cng/Diesel Dual-Fuel Combustion in a Light Duty Optical Diesel Engine". 2017, SAE Technical Paper 2017-01-0755, doi: http://dx.doi.org/10.4271/2017-01-0755.

13. Pettinen, R., Kaario, O., and Larmi, M., "Dual-Fuel Combustion Characterization on Lean Conditions and High Loads". 2017, SAE Technical Paper 2017-01-0759, doi: http://dx.doi.org/10.4271/2017-01-0759.

14. Dronniou, N., Kashdan, J., Lecointe, B., Sauve, K., et al., "Optical Investigation of Dual-Fuel Cng/Diesel Combustion Strategies to Reduce Co 2 Emissions." SAE International Journal of Engines, 2014. 7: p. 873-887, doi: http://dx.doi.org/10.4271/2014-01-1313.

15. Zhang, Y., Ghandhi, J., and Rothamer, D., "Effects of Fuel Chemistry and Spray Properties on Particulate Size Distributions from Dual-Fuel Combustion Strategies." SAE Int. J. Engines, 2017. 10(4): p. 1847-1858, doi: http://dx.doi.org/10.4271/2017-01-1005.

16. Ahmad, Z., Aryal, J., Ranta, O., Kaario, O., et al., "An Optical Characterization of Dual-Fuel Combustion in a HeavyDuty Diesel Engine." SAE Technical Paper 2018-01-0252, 2018, doi: http://dx.doi.org/10.4271/2018-01-0252.

17. Egúsquiza, J.C., Braga, S.L., and Braga, C.V.M., "Performance and Gaseous Emissions Characteristics of a Natural Gas/Diesel Dual Fuel Turbocharged and Aftercooled Engine." Journal of the Brazilian Society of Mechanical Sciences and Engineering, 2009. 31: p. 142-150, doi: http://dx.doi.org/10.1590/S1678-58782009000200007.

18. Schlatter, S., Schneider, B., Wright, Y., and Boulouchos, K., "Experimental Study of Ignition and Combustion Characteristics of a Diesel Pilot Spray in a Lean Premixed Methane/Air Charge Using a Rapid Compression Expansion Machine." SAE Technical Paper 2012-01-0825, 2012, doi: http://dx.doi.org/10.4271/2012-01-0825.

19. Salaun, E., Apeloig, J., Grisch, F., Yvonnet, C.-E., et al. "Optical Investigation of Ignition Timing and Equivalence Ratio in Dual-Fuel Cng/Diesel Combustion". 2016. SAE Technical Paper 2016-01-0772, doi: http://dx.doi.org/10.4271/2016-01-0772.

20. Srna, A., Bruneaux, G., von Rotz, B., Bombach, R., et al., "Optical Investigation of Sooting Propensity of N-Dodecane Pilot/Lean-Premixed Methane Dual-Fuel Combustion in a Rapid Compression-Expansion Machine." SAE Technical Paper 2018-01-0258, 2018, doi: http://dx.doi.org/10.4271/2018-01-0258.

21. Srna, A., Barro, C., Herrmann, K., Möri, F., et al., "Pomdme as an Alternative Pilot Fuel for Dual-Fuel Engines: Optical Study in a Rcem and Application in an Automotive Size Dual-Fuel Diesel Engine." SAE Technical Paper 2018-011734, 2018, doi: http://dx.doi.org/10.4271/2018-01-1734.

22. Rochussen, J., Yeo, J., and Kirchen, P., "Effect of Fueling Control Parameters on Combustion and Emissions Characteristics of Diesel-Ignited Methane Dual-Fuel Combustion". 2016, SAE Technical Paper 2016-01-0792, doi: http://dx.doi.org/10.4271/2016-01-0792.

23. Karim Ghazi, A., "Combustion in Gas-Fueled Compression Ignition Engines of the Dual Fuel Type." 2010: p. 213-235, doi: http://dx.doi.org/10.1002/9783527628148.hoc047.

24. Srna, A., Bolla, M., Wright, Y.M., Herrmann, K., et al., "Effect of Methane on Pilot-Fuel Auto-Ignition in Dual-Fuel Engines." Proceedings of the Combustion Institute, 2018. 37, doi: http://dx.doi.org/10.1016/j.proci.2018.06.177.

25. Barro, C., Nani, C., Hutter, R., and Boulouchos, K., "Spray Model Based Phenomenological Combustion Description and Experimental Validation for a Dual Fuel Engine". 2017, SAE International, doi: http://dx.doi.org/10.4271/2017-24$\underline{0098}$.

26. Kahila, H., Wehrfritz, A., Kaario, O., and Vuorinen, V., "Large-Eddy Simulation of Dual-Fuel Ignition: Diesel Spray Injection into a Lean Methane-Air Mixture." Combustion and Flame, 2019. 199: p. 131-151, doi: http://dx.doi.org/10.1016/j.combustflame.2018.10.014.

27. Liu, Z. and Karim, G.A., "The Ignition Delay Period in Dual Fuel Engines". 1995, SAE International, doi: http://dx.doi.org/10.4271/950466.

28. Rochussen, J. and Kirchen, P., "Characterization of Reaction Zone Growth in an Optically Accessible Heavy-Duty Diesel/Methane Dual-Fuel Engine." International Journal of Engine Research, 2018: p. In press, 2019, doi: http://dx.doi.org/10.1177/1468087418756538.

29. Soriano, B.S., Richardson, E.S., Schlatter, S., and Wright, Y.M., "Conditional Moment Closure Modelling for DualFuel Combustion Engines with Pilot-Assisted Compression Ignition." SAE Technical Paper 2017-01-2188, 2017, doi: http://dx.doi.org/10.4271/2017-01-2188.

30. Soriano, B.S. and Richardson, E.S., "Investigation of Flame Propagation in Autoignitive Blends of N-Heptane and Methane Fuel." Combustion Science and Technology. Under Review. 
31. Khosravi, M., Rochussen, J., Yeo, J., Kirchen, P., et al. "Effect of Fuelling Control Parameters on Combustion

32. Barro, C., Lucjan, A., Li, Z., Kyrtatos, P., et al., "Development and Experimental Validation of a Fast Spray Ignition Model for Diesel Engines Using Insights from Cfd Spray Calculations." SAE International Journal of Fuels and Lubricants, 2017. 10(2): p. 304-317, doi: http://dx.doi.org/10.4271/2017-01-0812.

33. Kokjohn, S.L., Musculus, M.P.B., and Reitz, R.D., "Evaluating Temperature and Fuel Stratification for Heat-Release Rate Control in a Reactivity-Controlled Compression-Ignition Engine Using Optical Diagnostics and Chemical Kinetics Modeling." Combustion and Flame, 2015. 162(6): $\quad$ p. http://dx.doi.org/10.1016/j.combustflame.2015.04.009.

34. Liu, H., Tang, Q., Ran, X., Fang, X., et al., "Optical Diagnostics on the Reactivity Controlled Compression Ignition (Rcci) with Micro Direct-Injection Strategy." Proceedings of the Combustion Institute, 2018, doi: http://dx.doi.org/10.1016/j.proci.2018.06.180.

35. Reitz, R.D. and Duraisamy, G., "Review of High Efficiency and Clean Reactivity Controlled Compression Ignition (Rcci) Combustion in Internal Combustion Engines." Progress in Energy and Combustion Science, 2015. 46: p. 12-71, doi: http://dx.doi.org/10.1016/i.pecs.2014.05.003.

36. Vallinayagam, R., An, Y., S.Vedharaj, Sim, J., et al., "Naphtha Vs. Dieseline - the Effect of Fuel Properties on Combustion Homogeneity in Transition from Ci Combustion Towards Hcci." Fuel, 2018. 224: p. 451-460, doi: http://dx.doi.org/10.1016/i.fuel.2018.03.123.

37. Goyal, H., Kook, S., and Ikeda, Y., "The Influence of Fuel Ignition Quality and First Injection Proportion on Gasoline Compression Ignition (Gci) Combustion in a Small-Bore Engine." Fuel, 2019. 235: p. 1207-1215, doi: http://dx.doi.org/10.1016/j.fuel.2018.08.090.

38. Kammermann, T., Koch, J., Wright, Y.M., Soltic, P., et al., "Generation of Turbulence in a Rcem Towards Engine Relevant Conditions for Premixed Combustion Based on Cfd and Piv Investigations." SAE International Journal of Engines, 2017. 10(4), doi: http://dx.doi.org/10.4271/2017-24-0043.

39. Seume, J. and Mailach, R., "Grundlagen Der Strömungsmaschinen", in Dubbel: Taschenbuch Für Den Maschinenbau, K.-H. Grote and J. Feldhusen, Editors. 2014, Springer Berlin Heidelberg: Berlin, Heidelberg. p. 1250-1277.

40. Schlatter, S., Schneider, B., Wright, Y.M., and Boulouchos, K., "N-Heptane Micro Pilot Assisted Methane Combustion in a Rapid Compression Expansion Machine." Fuel, 2016. 179: p. 339-352, doi: http://dx.doi.org/10.1016/j.fuel.2016.03.006.

41. Musculus, M.P. and Kattke, K., "Entrainment Waves in Diesel Jets." SAE International Journal of Engines, 2009. 2: p. 1170-1193, doi: http://dx.doi.org/10.4271/2009-01-1355.

42. Malbec, L.-M., Eagle, W.E., Musculus, M.P.B., and Schihl, P., "Influence of Injection Duration and Ambient Temperature on the Ignition Delay in a 2.341 Optical Diesel Engine." SAE Int. J. Engines, 2015. 9(1): p. 47-70, doi: http://dx.doi.org/10.4271/2015-01-1830.

43. Miles, P.C., Sahoo, D., Busch, S., Trost, J., et al., "Pilot Injection Ignition Properties under Low-Temperature, Dilute inCylinder Conditions." SAE International Journal of Engines, 2013. 6(4): p. 1888-1907, doi: http://dx.doi.org/10.4271/2013-01-2531.

44. Idicheria, C.A. and Pickett, L.M., "Ignition, Soot Formation, and End-of-Combustion Transients in Diesel Combustion under High-Egr Conditions." International Journal of Engine Research, 2011. 12(4): p. 376-392, doi: http://dx.doi.org/10.1177/1468087411399505.

45. Idicheria, C.A. and Pickett, L.M., "Effect of Egr on Diesel Premixed-Burn Equivalence Ratio." Proceedings of the Combustion Institute, 2007. 31(2): p. 2931-2938, doi: http://dx.doi.org/10.1016/j.proci.2006.08.022.

46. Desantes, J.M., Pastor, J.V., Garcia-Oliver, J.M., and Pastor, J.M., "A 1d Model for the Description of MixingControlled Reacting Diesel Sprays." Combustion and Flame, $2009 . \quad 156(1)$ : p. 234-249, doi: http://dx.doi.org/10.1016/j.combustflame.2008.10.008.

47. Siebers, D.L., "Liquid-Phase Fuel Penetration in Diesel Sprays". 1998, SAE Technical Paper 98-0809, doi: http://dx.doi.org/10.4271/980809.

48. Skeen, S.A., Manin, J., and Pickett, L.M., "Simultaneous Formaldehyde Plif and High-Speed Schlieren Imaging for Ignition Visualization in High-Pressure Spray Flames." Proceedings of the Combustion Institute, 2015. 35: p. 31673174, doi: http://dx.doi.org/10.1016/i.proci.2014.06.040.

49. Bardi, M., Payri, R., Malbec, L.M.C., Bruneaux, G., et al., "Engine Combustion Network: Comparison of Spray Development, Vaporization, and Combustion in Different Combustion Vessels." 2012. 22(10): p. 807-842, doi: http://dx.doi.org/10.1615/AtomizSpr.2013005837.

50. $\quad$ Pickett, L.M., "Engine Combustion Network." http://www.sandia.qov/ecn/dieselSprayCombustion.php, 2013.

51. Kim, T., Beckman, M.S., Farrell, P.V., and Ghandhi, J.B., "Evaporating Spray Concentration Measurementsfrom Small and Medium Bore Diesel Injectors". 2002, SAE International, doi: http://dx.doi.org/10.4271/2002-01-0219.

52. Yeh, C.-N., Kamimoto, T., Kosaka, H., and Kobori, S., "Quantitative Measurement of 2-D Fuel Vapor Concentration in a Transient Spray Via Laser-Induced Fluorescence Technique". 1994, SAE Technical Paper 94-1953, doi: http://dx.doi.org/10.4271/941953.

53. Senda, J., Kanda, T., Kobayashi, M., and Fujimoto, H., "Quantitative Analysis of Fuel Vapor Concentration in Diesel Spray by Exciplex Fluorescence Method." SAE Technical Papers 970796, 1997. 970796, doi: http://dx.doi.org/10.4271/970796. 


\begin{abstract}
54. Bruneaux, G., "Mixing Process in High Pressure Diesel Jets by Normalized Laser Induced Exciplex Fluorescence Part I: Free Jet". 2005, SAE Technical Paper 2005-01-2100, doi: http://dx.doi.org/10.4271/2005-01-2100.

55. Desantes, J.M., Pastor, J.V., Pastor, J.M., and Juliá, J.E., "Limitations on the Use of the Planar Laser Induced Exciplex Fluorescence Technique in Diesel Sprays." Fuel, 2005. 84: p. 2301-2315, doi: http://dx.doi.org/10.1016/j.fuel.2005.05.009.
\end{abstract}

\title{
7 Abbreviations:
}

$\left[\mathrm{O}_{2}\right] \quad$ Charge oxygen concentration [vol \%]

aSOI after Start of Injection

BDC Bottom Dead Center

EGR Exhaust Gas Recirculation

EOI End of Injection

eSOI Electronic start of injection

ET injector Energizing Time

FHWM Full-Width at Half-Maximum

HRR Heat Release Rate

ID Ignition Delay

LHV Lower Heating Value

$\mathrm{m}_{\mathrm{v}} \quad$ Wiebe-function shape parameter

$\mathrm{NO}_{\mathrm{x}} \quad$ Nitrogen oxides

$\mathrm{p}_{\text {ini }} \quad$ Injection pressure

PIV Particle Image Velocimetry

PLIF Planar Laser-Induced Fluorescence

RCCI Reactivity-Controlled Compression Ignition

RCEM Rapid Compression-Expansion Machine

SOI hydraulic Start of Injection

TDC Top Dead Center

TMPD N,N,N',N' -tetramethyl-pphenilenediamine

$\mathrm{T}_{\text {SOI }} \quad$ Charge temperature at SOI

$\mathrm{t}_{\mathrm{v}} \quad$ Pilot-fuel combustion duration metric

UHC Unburnt HydroCarbons

$\phi_{\mathrm{CH} 4} \quad$ Charge methane equivalence ratio 


\section{Appendix A: TMPD tracer-PLIF methodology}

The fuel distribution in case of short transient injections was shown to strongly depend on the end-of-injection transient with enhanced entrainment $[41,46]$. It also depends on the injector dynamics like needle motion. The mass flow rate of the injector used in the present study was characterized using a 'Bosch-tube' type analyzer. Nevertheless, to provide higher-fidelity information about the pilot mixing in the RCEM test-rig geometry, a dedicated set of experiments under non-reactive conditions was performed. This section describes the quantitative tracer-PLIF imaging approach used to characterize the pilot-fuel mixing.

\section{A.1: TMPD Tracer-PLIF optical setup}

TMPD was selected as the tracer substance for its advantages of excitation at $355 \mathrm{~nm}$, high-fluorescent yield under high temperatures, and tracer thermo-physical properties similar to the properties of n-dodecane. To prevent tracer quenching by oxygen and achieve non-reactive conditions the RCEM charge consisted of pure nitrogen. Also, the fuel-supply system was purged with a constant flow of nitrogen to prevent oxygen from dissolving in the fuel.

Figure 14 shows the optical setup for simultaneous high-speed tracer-PLIF, Mie-scattering, and Schlieren images as applied at the RCEM. Tracer-PLIF imaging provided quantitative information on the pilot-fuel concentration within the laser-sheet plane. This information was complemented by Mie-scattering imaging information on the liquidphase extent of the spray for every single PLIF image and by Schlieren imaging information on the overall extent of the pilot-fuel jet. The view of the three optical diagnostic methods was along the same optical axis aligned with the cylinder axis. All devices were synchronized to the electronic start of injection (eSOI, $0.36 \mathrm{~ms}$ before hydraulic SOI) using a programmable timing unit (LaVision HS controller).

\section{A.1.1: TMPD tracer-PLIF}

Tracer-PLIF investigations were performed under non-reactive conditions using n-dodecane pilot-fuel doped with $1.5 \mathrm{~g} / 1$ TMPD tracer. Tracer fluorescence was excited with the $355 \mathrm{~nm} 3^{\text {rd }}$ harmonic output of a high-speed diodepumped Nd:YAG laser (Edgewave IS400) at $10 \mathrm{kHz}$ rate and pulse energy of $7 \mathrm{~mJ} /$ pulse. The laser beam was shaped into an around $1 \mathrm{~mm}$ thick and $50 \mathrm{~mm}$ high laser-sheet using a combination of cylindrical and spherical lenses. The central $30 \mathrm{~mm}$ of the sheet were directed into the combustion chamber at an angle of $3.5^{\circ}$ from the firedeck. This optimal angle was determined based on the tomographic detection of ignition delay and accounts for the pilot-fuel plume compression and shifting by the piston motion.

Fluorescence was detected using an intensified high-speed camera system (LaVision HS-IRO coupled to Photron FastCam SA1.1 camera) equipped with a $100 \mathrm{~mm} \mathrm{f} / 2.8 \mathrm{UV}$ lens (Sodern Cerco). The projected pixel size was $0.11 \mathrm{~mm} /$ pixel. A bandpass filter ( $400 \mathrm{~nm}$ central wavelength, $50 \mathrm{~nm}$ full-width half-maximum) has been used to separate the PLIF signal from the scattered laser light and environment light. Intensifier gate of $100 \mathrm{~ns}$ was used throughout this study while the gain was adapted between 3-20 counts/photoelectron to prevent the camera overexposure and ensure sufficient signal-to-noise ratio. The tracer-PLIF signal was then quantified to yield fuelconcentration by accounting for the image white-field, pulse intensity, information on the total injected fuel and tracer quantum-yield dependence on temperature. The exact quantification procedure is described in detail in Section A.2.

\section{A.1.2: Mie-scattering}

Liquid-phase Mie-scattering of the $355 \mathrm{~nm}$ laser sheet was detected at $10 \mathrm{kHz}$ using a high-speed camera (Photron FastCam SA1.1) equipped with a $105 \mathrm{~mm} \mathrm{f} / 4.1 \mathrm{UV}$ lens (Coastal Optics) and $355 \mathrm{~nm}$ bandpass filter $(10 \mathrm{~nm}$ FWHM, BK Interferenzoptik). Due to the abundance of scattered light aperture setting of $\mathrm{f} / 11$ was used throughout the study. The image resolution was $0.17 \mathrm{~mm} /$ pixel.

Images are then processed to determine the regions with presence of the liquid: First, background images acquired prior to the SOI were subtracted to remove the light scattered on the cylinder wall. Then, a threshold of $3 \%$ of the camera dynamic range was chosen to distinguish the liquid spray from the remaining background intensity in 
accordance to Siebers [47]. This threshold was found to reliably discriminate the liquid spray from the background scattering and camera noise.

\section{A.1.3: Schlieren imaging}

Schlieren imaging has been performed at a frame rate of $80 \mathrm{kHz}$ with a projected pixel size of $0.16 \mathrm{~mm} /$ pixel. A fiber-coupled pulsed laser diode array (Cavilux Smart, wavelength $690 \pm 10 \mathrm{~nm}, 10 \mathrm{~ns}$ pulse duration, $440 \mathrm{~W}$ output) illuminating a close-coupled diffusor plate and a $1 \mathrm{~mm}$ diameter pinhole has been used to generate a point light source. This light has been collimated using a $400 \mathrm{~mm}$ focal length achromatic lens and directed along the cylinder axis through the combustion chamber. The collimated beam has been refocused using another achromatic lens of the same type. An aperture diameter of $3 \mathrm{~mm}$ in the lens focal point has been used as a Schlieren stop. After passing the Schlieren stop the light was recorded with a high-speed camera (Photron Fastcam SA-X2) equipped with a Nikkor $50 \mathrm{~mm} \mathrm{f} / 1.4$ lens to achieve the desired image scale. The camera exposure time was $1 \mu \mathrm{s}$; the lens was equipped with a $690 \mathrm{~nm}$ bandpass filter to suppress the flame luminosity. The aperture sizes of $1 \mathrm{~mm}$ and $3 \mathrm{~mm}$ were selected to achieve a sufficient contrast of the Schlieren images by an empirical approach, as described in [48], resulting in similar beam-divergence tolerance of the system as in other comparable studies [40, 49]. Due to hardware obstructions between the piston and mirror the region closer than $22 \mathrm{~mm}$ to the injector orifice is not visibly accessible.

Image processing of Schlieren images was based on the adaptive background subtraction approach proposed by the Engine Combustion Network community [50]. The threshold setting in the adaptive background processing routines was chosen in an empirical procedure until the methodology reliably discriminated spray from the background.

\section{A.2: Tracer-PLIF quantification}

To obtain quantitative information on the pilot-fuel concentration using tracer-PLIF technique (1) the influence of the compression heating and evaporative cooling on the tracer quantum yield has to be accounted for, (2) the camera white-field and laser-sheet profile corrections have to be performed and (3) camera pixel-counts have to be correlated to the absolute pilot-fuel concentration. This appendix section describes the quantification approach of this study and demonstrates the quality of quantification.

First, the camera while field and laser pulse energy were addressed: A homogeneously seeded TMPD vapor has been introduced into the RCEM combustion chamber using a heated bubbler. The temperature of TMPD in the bubbler was adjusted so that similar PLIF signal intensity has been detected as during the actual fuel-vapor PLIF acquisitions. Flow through the bubbler was kept constant using a mass-flow controller. These images provided the camera white-field and laser-sheet profile correction. Additionally, such images can be used to estimate the pulse-topulse fluctuation of the laser-sheet. The top-hat beam of the employed laser (Edgewave IS400) with dimensions of $3 \times 8 \mathrm{~mm}$ is very homogeneous along the short dimension and structured along the longer edge. This structure contains many peaks and varies between pulses. Therefore, the laser beam was expanded along the short dimension and focused along the long direction using a combination of cylindrical and spherical lenses. Very small shot-to-shot fluctuations of the laser sheet profile were detected and therefore we did not acquire the sheet-profile for each pulse separately. It has to be noted that along the thickness of the laser sheet rather large fluctuations are expected, however at the present resolution we do not believe that such fluctuations would influence the acquisition. Rather small pulse-energy fluctuations $(3 \% \mathrm{rms})$ were monitored online during acquisitions with a fast photodiode and SRS Boxcar integrator.

The correction for the compression heating was done using the bulk temperature of charge taken from the thermodynamic model. The adiabatic mixing model was applied to correct the temperature of air/fuel mixture due to the evaporative cooling and mixing of the cold liquid fuel. Literature data on the fluorescence yield dependency on temperature from [51] was used after a literature review of the available datasets for TMPD: [51-53]. All datasets are in a good agreement. Nevertheless, only [51] measured the fluorescence yield over the whole temperature range of interest in this study using a setup with a short residence time of tracer to avoid the tracer thermal decomposition. 
The temperature and the fuel concentration were then determined iteratively using the adiabatic mixing according to the procedure proposed by Bruneaux et al. [54].

In the last stage, the camera pixel-counts were related to the absolute fuel concentration. Literature applying tracerPLIF for sprays in constant volume chamber [54, 55] suggests using the total injected fuel mass after the end of injection and axi-symmetric assumption to iteratively calibrate the detected tracer signal into fuel-concentration which integrated equals the injected fuel mass. In the case of RCEM with the piston movement during the injection, the axi-symmetric assumption might not apply anymore. Also, part of the fuel-spray will be shifted outside of the laser sheet. Therefore measurements were performed at 7 laser-sheet positions at $2 \mathrm{~mm}$ spacing parallel to the cylinder head surface, as drawn in Figure 15. This way the whole spray extent was captured by these planes. Calibration was then performed by summing the fuel-concentration from all 7 planes together and the pixel-count to fuel concentration adapted so that the total fuel-concentration was captured correctly.

Considering several laser-sheet planes and different camera-gain and aperture settings necessary for different acquisitions, a reference PLIF signal was needed for different camera settings. Again the PLIF signal of the homogeneously seeded TMPD vapor was used for this purpose and was acquired after each change of the camera settings or laser-sheet shift. The temperature of the bubbler was kept constant to achieve constant tracer concentration.

As a measure of the quality of PLIF quantification, the temporal evolution of the total detected fuel-vapor is plotted in Figure 16 and compared to the total injected mass from the injection-rate analyzer. The time at $1.5 \mathrm{~ms}$ aSOI was selected as the reference point at which the tracer-PLIF was calibrated. In case of perfect quantification after EOI (end of injection) the total fuel concentration should remain constant. In the interval between the end of injection and $2.5 \mathrm{~ms}$ aSOI, the quantification was deemed successful. However, shortly before EOI, up to $20 \%$ overshoot of the total mass was detected. This initial overshoot was attributed to scattering of very intense liquid-spray PLIF signal on the combustion chamber walls. We were unable to remove this interference efficiently. Beyond $2.5 \mathrm{~ms}$ aSOI the pilot-spray becomes very dilute, charge temperature very high (exceeding $1000 \mathrm{~K}$ ) and the signal very weak. The large contribution of noise is believed to contribute to this overprediction late in the cycle. 


\section{Figures:}

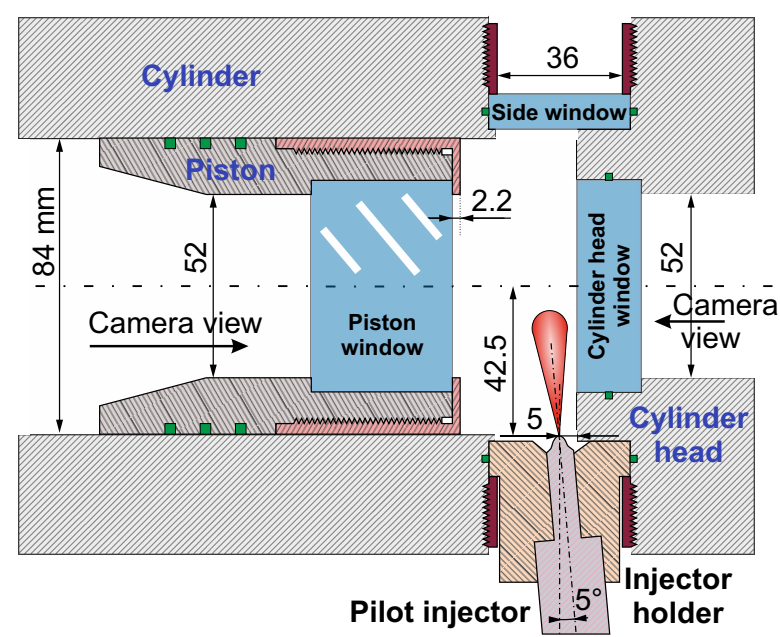

Figure 1: RCEM combustion chamber geometry. Dimensions in mm.

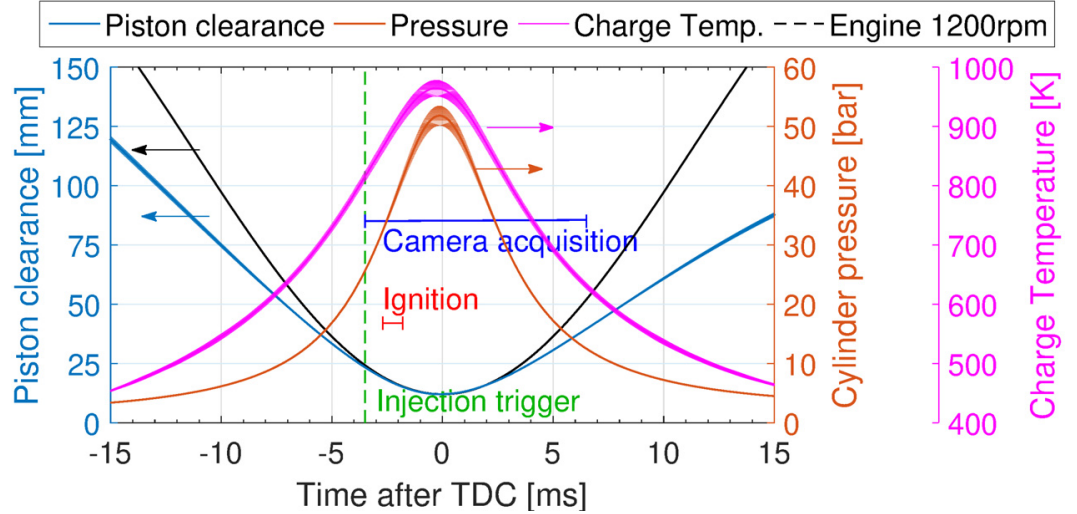

Figure 2: Piston position, in-cylinder pressure trace, and charge temperature evolution averaged over 100 non-reactive cycles. $1 \times \sigma$ variability of traces is demonstrated by the shaded regions. Stroke of an engine running at 1200 RPM is shown with the gray dashed line for reference. Injection timing is marked with a green line. 

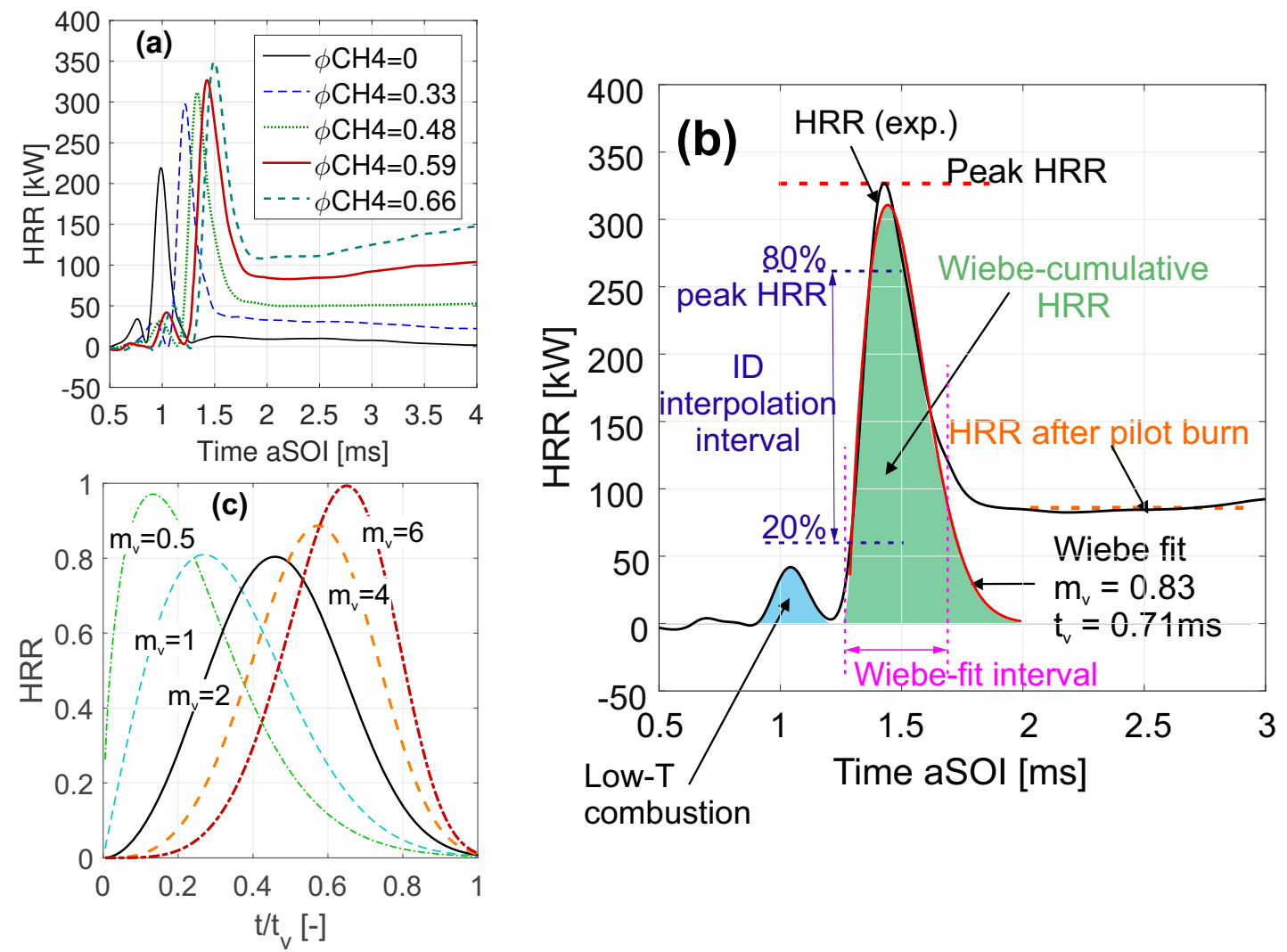

Figure 3: (a) HRR curves for a variation of $\phi_{\mathrm{CH} 4}$ at $T_{\mathrm{SOI}}=810 \mathrm{~K}, \mathrm{ET}=400 \mu \mathrm{s}$, (b) schematic of the HRR metrics, ID detection and Vibe fitting to the HRR, and (c) plot of the Wiebe-function shape for different values of the shape parameter $\mathbf{m}_{\mathrm{v}}$.

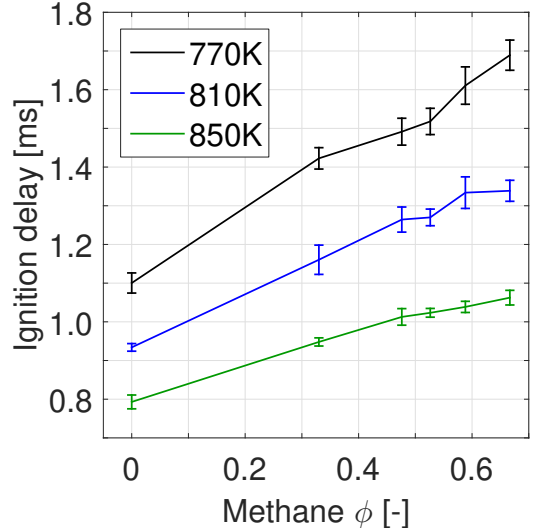

(a) $\mathrm{T}_{\mathrm{SOI}}$ variation, $\mathrm{ET}=400 \mathrm{~ms}$

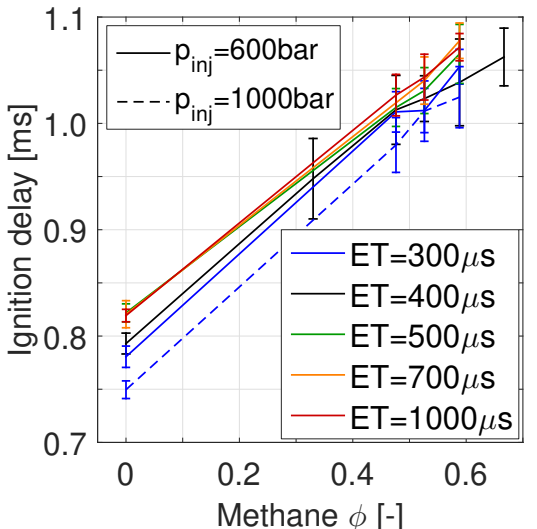

(b) ET variation, $\mathrm{T}_{\mathrm{SOI}}=850 \mathrm{~K}$

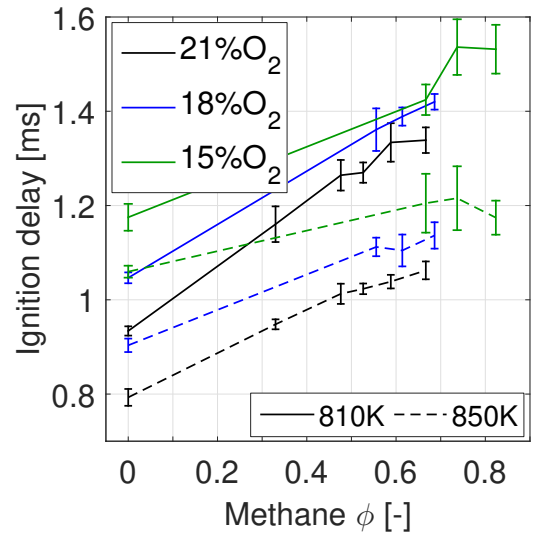

(c) $\left[\mathrm{O}_{2}\right]$ variation, $\mathrm{ET}=400 \mu \mathrm{s}$

Figure 4: Influence of charge methane $\phi_{\mathrm{CH} 4}$ on the pilot-fuel ignition delay for a variation of $\mathrm{T}_{\mathrm{SOI}}(\mathrm{a})$, injection $\mathrm{ET}$ (b) and charge oxygen content (c). Error bars indicate the standard deviation of the detected ID times. 


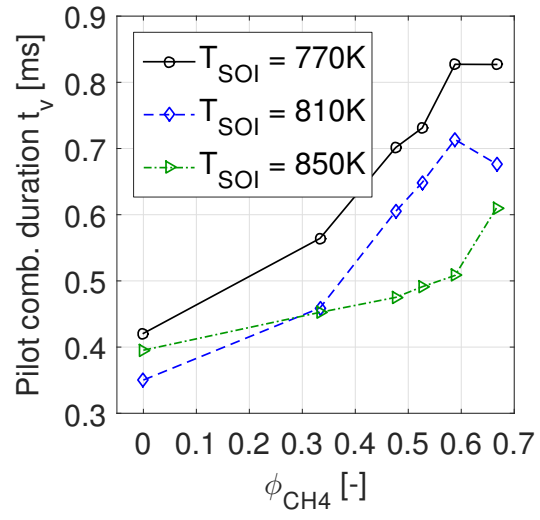

(a) Pilot combustion duration

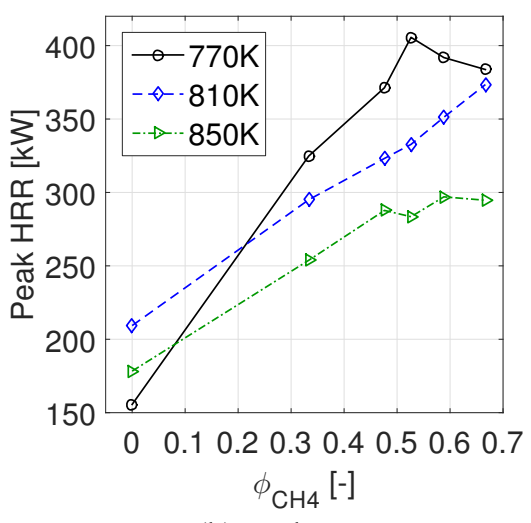

(b) Peak HRR

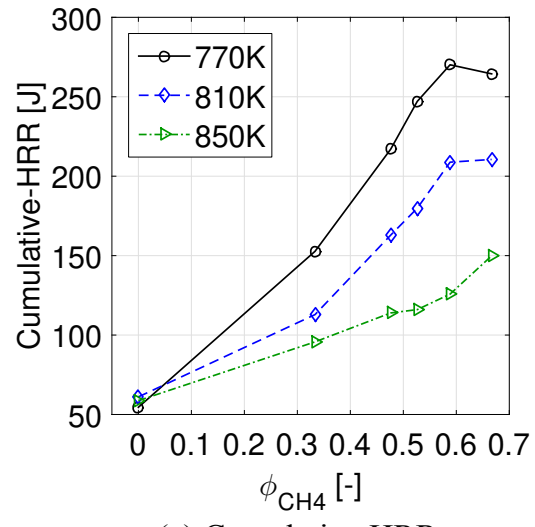

(c) Cumulative HRR

Figure 5: Dependence of HRR metrics for a variation of $\mathrm{T}_{\text {SOI. }}$. Injection parameters: $\mathrm{ET}=400 \mu \mathrm{s}, \mathrm{p}_{\mathrm{inj}}=600 \mathrm{bar}$

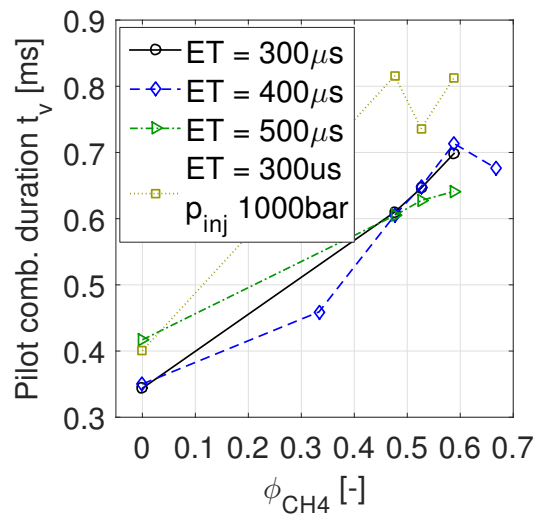

(a) Pilot combustion duration

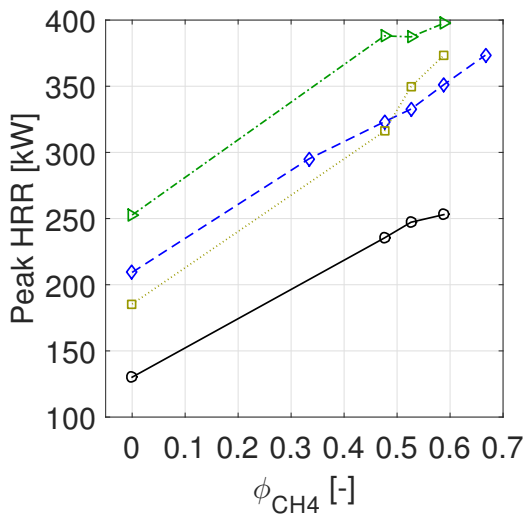

(b) Peak HRR

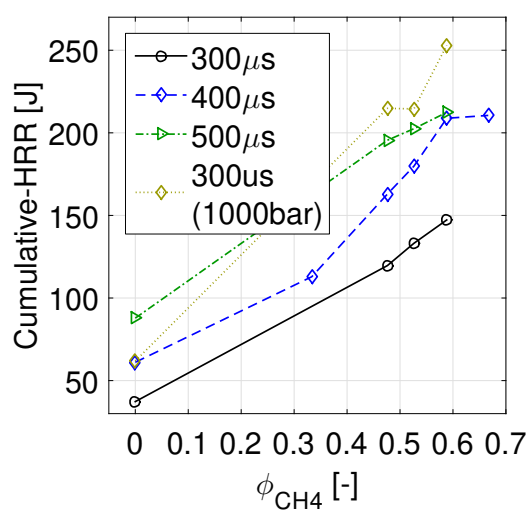

(c) Cumulative HRR

Figure 6: Dependence of HRR metrics for a variation of injection $\mathrm{ET}$ and $\mathrm{p}_{\mathrm{inj}}$ at $\mathrm{T}_{\mathrm{SOI}}=\mathbf{8 1 0} \mathrm{K}$.

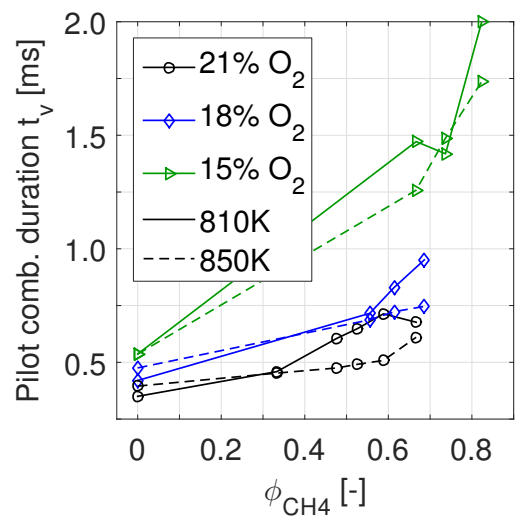

(a) Pilot combustion duration

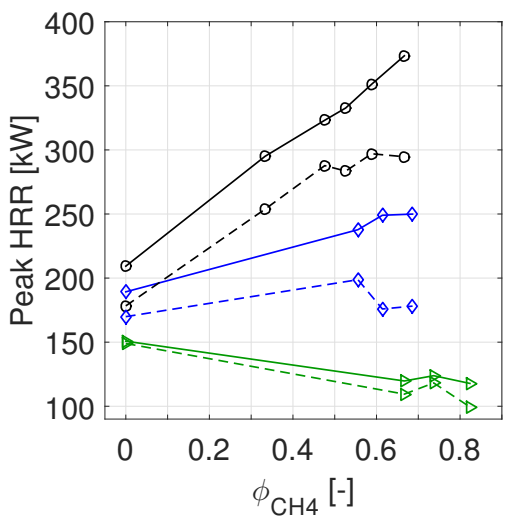

(b) Peak HRR

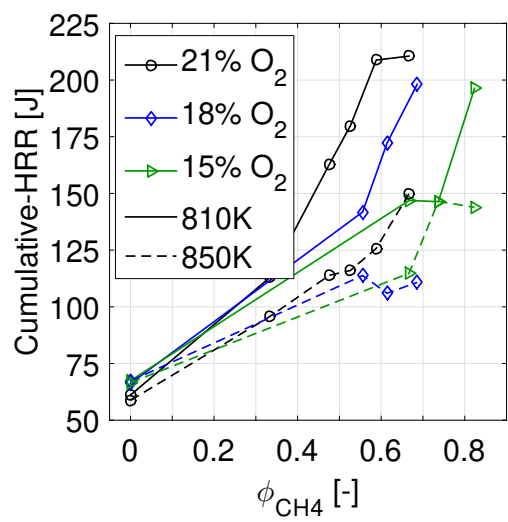

(c) Cumulative HRR

Figure 7: Dependence of HRR metrics for a variation charge oxygen content. Injection parameters: $\mathbb{E T}=400 \mu \mathrm{s}, \mathrm{p}_{\mathrm{inj}}=600 \mathrm{bar}$ 

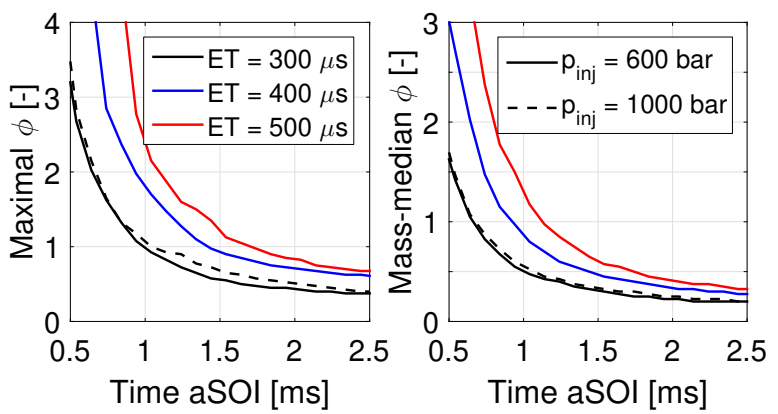

Figure 8: Temporal evolution of maximal (left) and fuel-mass median (right) pilot-fuel equivalence ratio for a variation of injector ET and $\mathrm{p}_{\text {inj. }}$
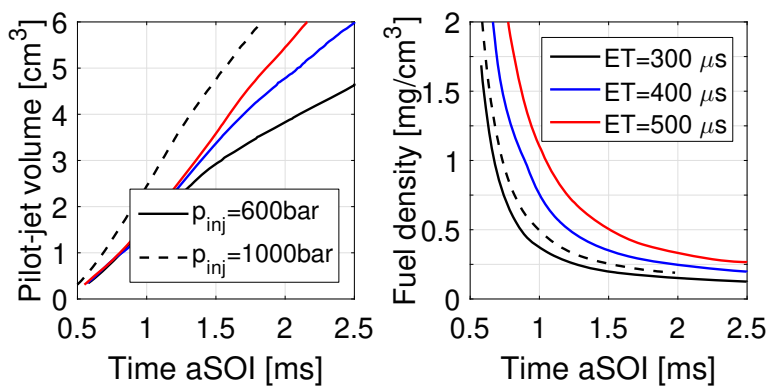

Figure 9: Evolution of pilot-spray plume volume (left) and pilot-fuel density (right) for a variation of injector ET and $\mathbf{p}_{\mathrm{inj}}$.
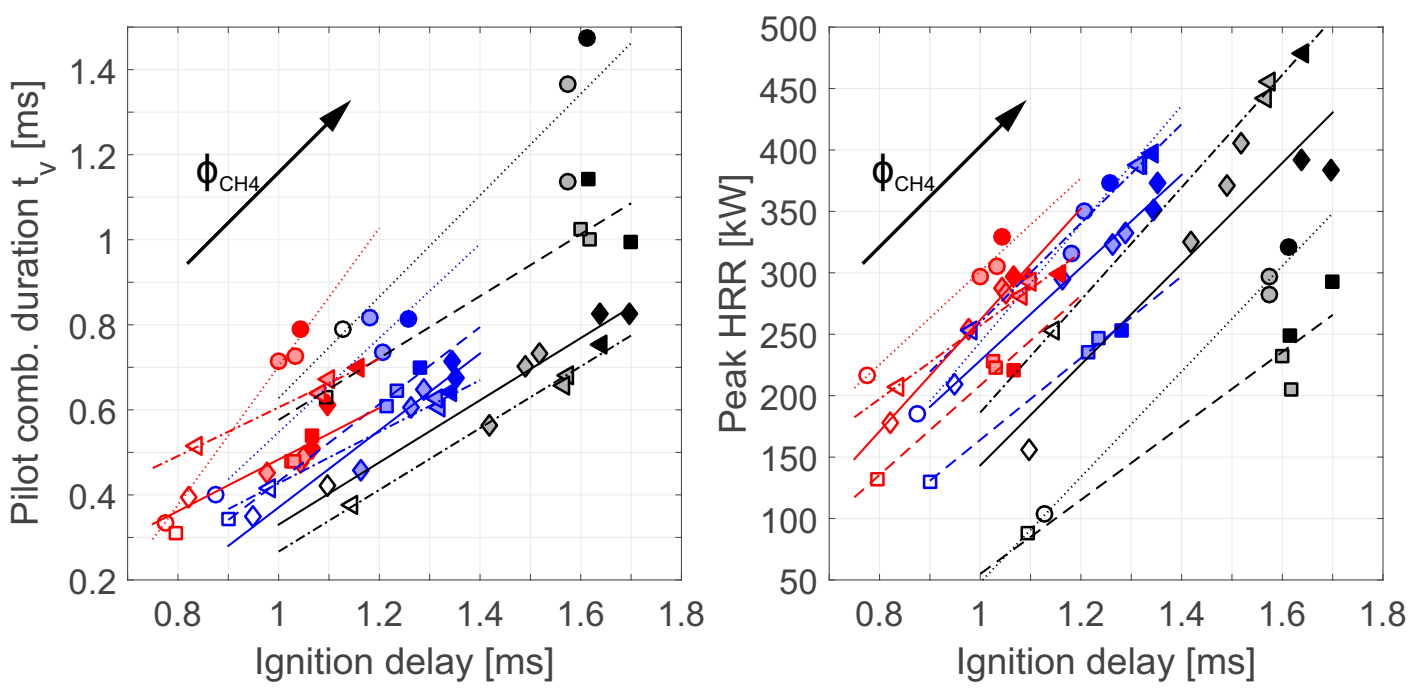

- в-ET = 300us / 600bar

$\diamond$ ET $=400$ us / 600bar

-\&-ET = 500us / 600bar

……ET = 300us / 1000bar

$\mathrm{T}_{\mathrm{SOI}}=770 \mathrm{~K}$

$-\mathrm{T}_{\mathrm{SOI}}=810 \mathrm{~K}$

$-\mathrm{T}_{\mathrm{SOI}}=850 \mathrm{~K}$

$\circ \phi_{\mathrm{CH} 4}=0$

- $0.33 \leq \phi_{\mathrm{CH} 4} \leq 0.51$

- $0.59 \leq \phi_{\mathrm{CH} 4} \leq 0.66$

Figure 10: Correlation of pilot combustion duration $t_{v}$ to ignition delay (left) and correlation of the peak HRR to the ignition delay (right). Marker shape indicates the pilot injection parameters, marker color the $T_{\mathrm{SOI}}$, and marker fill the $\phi_{\mathrm{CH} 4}$, according to the legend. Lines are linear fits to the $\phi_{\mathrm{CH} 4}$ variation data-points at otherwise same conditions. 

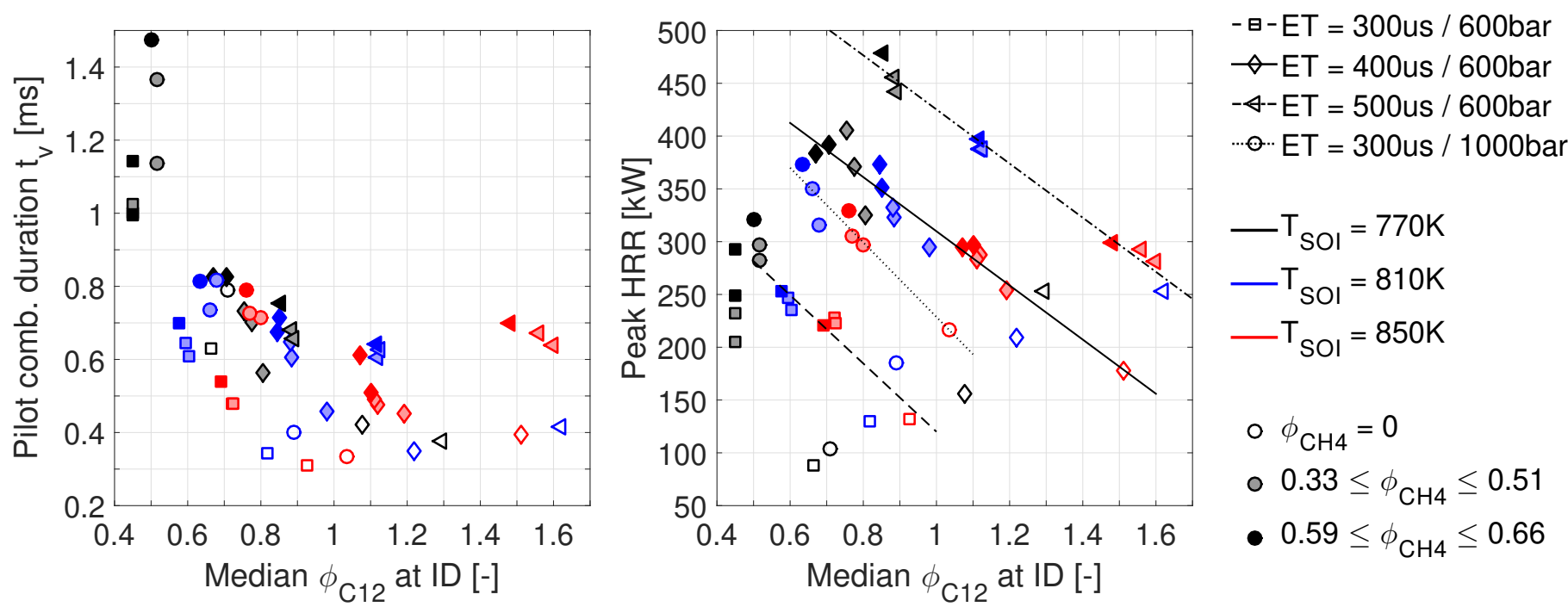

Figure 11: Correlation of $t_{v}$ (left) and peak-HRR (right) to the median equivalence ratio $\phi_{\mathrm{C} 12}$ at the time of ignition. Marker shape indicates the pilot injection, marker color the $\mathrm{T}_{\mathrm{SOI}}$, and marker fill the $\phi_{\mathrm{CH} 4}$, according to the legend.
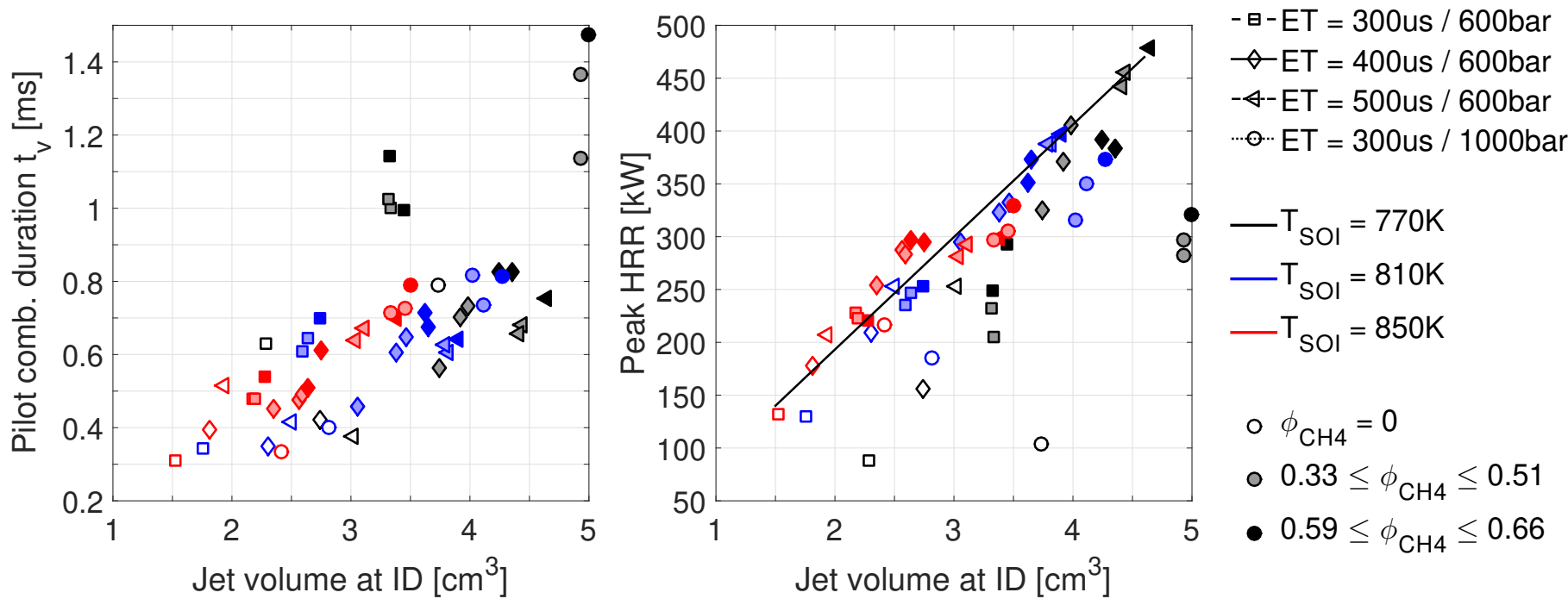

Figure 12: Correlation of $t_{v}$ (left) and peak-HRR (right) to the volume of the pilot-fuel jet at the time of ignition. Marker shape indicates the pilot injection strategy, marker color the $\mathrm{T}_{\mathrm{SO}}$, and marker fill the $\phi_{\mathrm{CH} 4}$, according to the legend. The black line on the right-plot was drawn manually to help visualize the upper-boundary of peak-HRR values. 

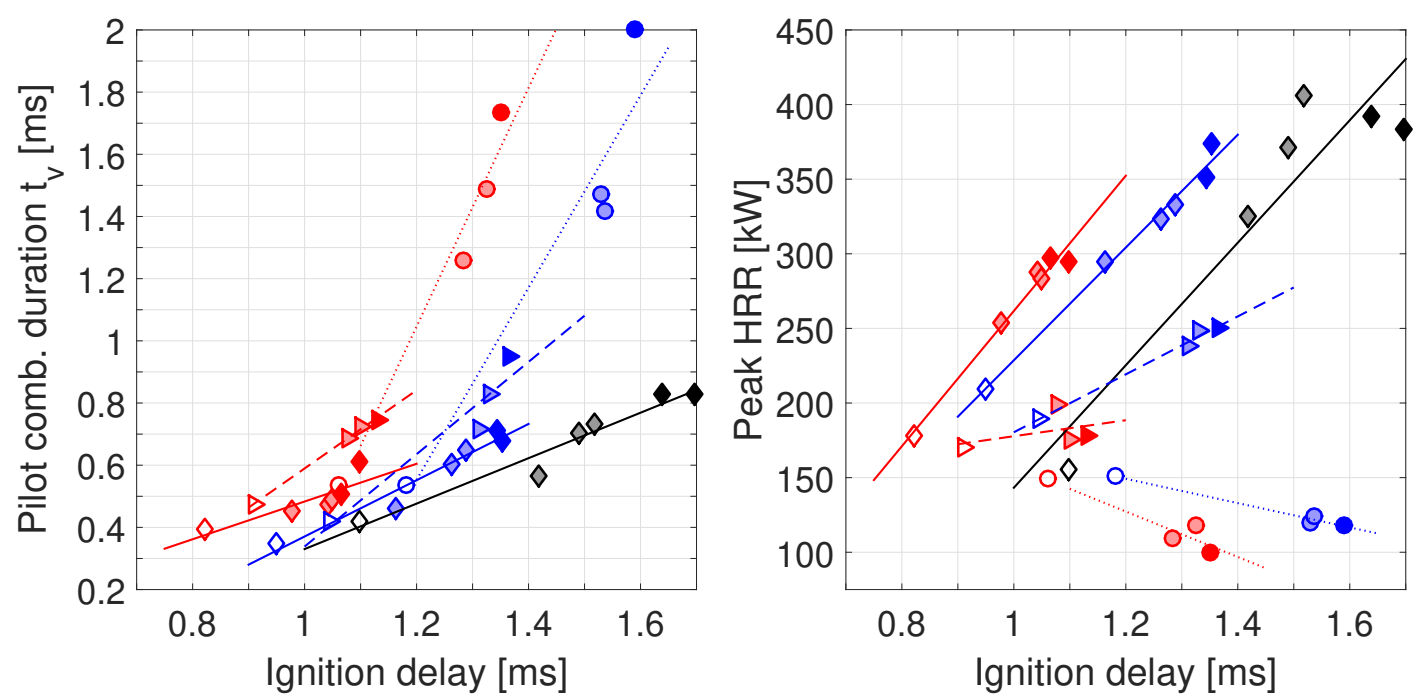

$$
\begin{aligned}
& \rightarrow 21 \%\left[\mathrm{O}_{2}\right] \\
& -\diamond-18 \%\left[\mathrm{O}_{2}\right] \\
& \cdots \odot 15 \%\left[\mathrm{O}_{2}\right] \\
& -\mathrm{T}_{\mathrm{SOI}}=770 \mathrm{~K} \\
& -\mathrm{T}_{\mathrm{SOI}}=810 \mathrm{~K} \\
& -\mathrm{T}_{\mathrm{SOI}}=850 \mathrm{~K} \\
& \circ \phi_{\mathrm{CH} 4}=0 \\
& \circ 0.33 \leq \phi_{\mathrm{CH} 4} \leq 0.51 \\
& -0.59 \leq \phi_{\mathrm{CH} 4} \leq 0.66
\end{aligned}
$$

Figure 13: Correlation of $t_{v}$ (left) and peak-HRR (right) to the ID for a variation of charge oxygen content [ $\left.\mathrm{O}_{2}\right]$. Marker shape indicates the charge oxygen content $\left[\mathrm{O}_{2}\right]$, marker color the $\mathrm{T}_{\mathrm{SOI}}$, and marker fill the $\phi_{\mathrm{CH} 4}$, according to the legend. Conditions: $\mathrm{ET}=400 \mu \mathrm{s}$, $\mathrm{p}_{\mathrm{inj}}=600 \mathrm{bar}$.

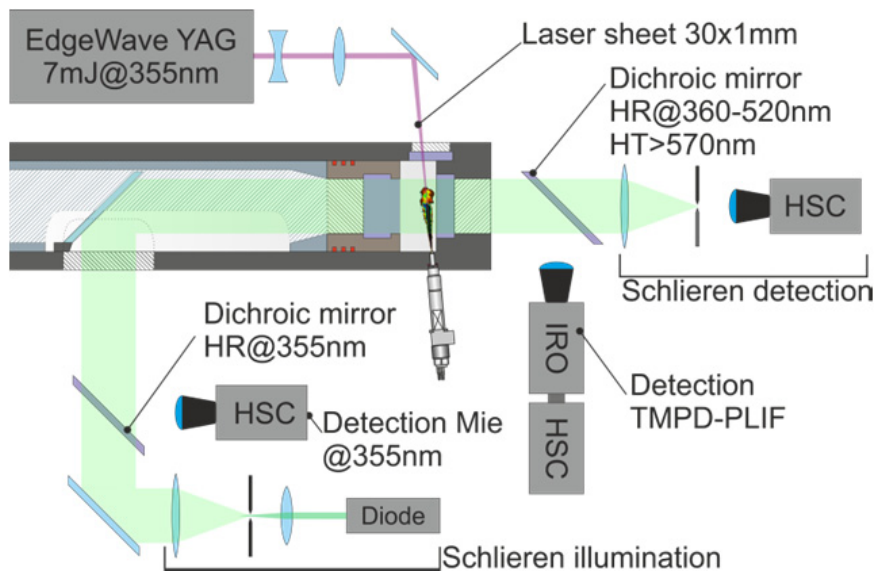

Figure 14: Schematic of the RCEM optical arrangement for simultaneous TMPD tracer-PLIF, Mie-scattering, and Schlieren imaging. 


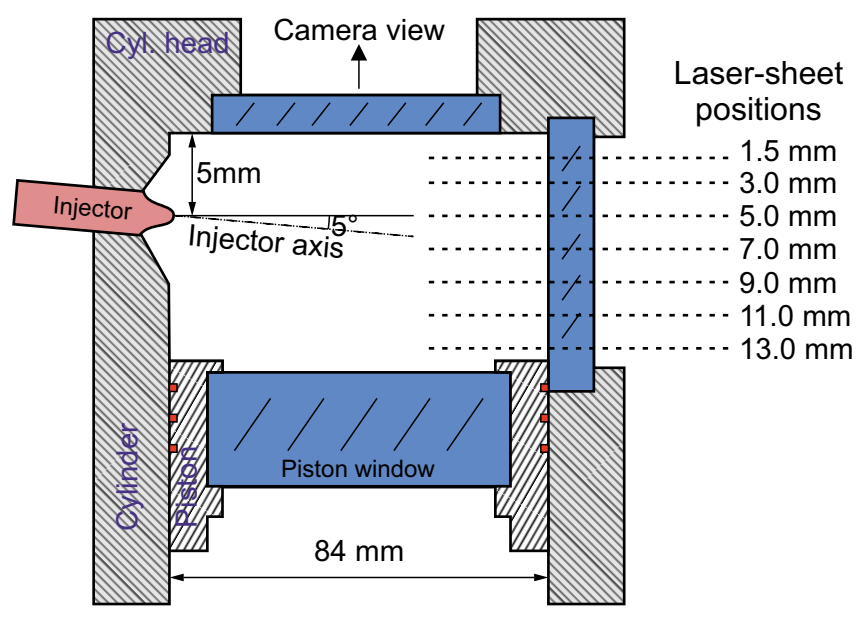

Figure 15: Sketch of the laser-sheet positions for quantification of tracer-PLIF images based on the total injected mass. Please note that the sketch proportions do not correspond to the actual geometry.

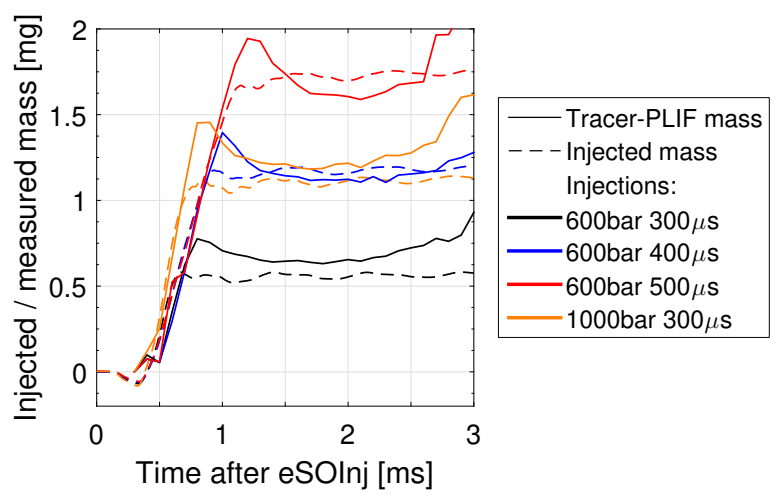

Figure 16: Tracer-PLIF calibration: the temporal evolution of the total detected fuel-mass compared to the injected fuel mass. 